\title{
Cartilage tissue engineering: From proinflammatory and anti-inflammatory cytokines to osteoarthritis treatments (Review)
}

\author{
SHUYU LIU ${ }^{1,2^{*}}$, ZHENHAN DENG $^{1,2^{*}}$, KANG CHEN $^{1,2}$, SHENGSHENG JIAN $^{3}$, FEIFEI ZHOU $^{1,2}$, \\ YUAN YANG $^{1,2}$, ZICAI FU $^{1,2}$, HUANYU XIE ${ }^{1,2}$, JIANYI XIONG ${ }^{1}$ and WEIMIN ZHU ${ }^{1,2}$ \\ ${ }^{1}$ Department of Sports Medicine, The First Affiliated Hospital of Shenzhen University, Shenzhen Second People's Hospital; \\ ${ }^{2}$ Shenzhen Sports Medicine Engineering Technology Research and Development Center, The First Affiliated Hospital of \\ Shenzhen University, Shenzhen Second People's Hospital, Shenzhen, Guangdong 518035; ${ }^{3}$ Department of Orthopedics, \\ Luo Hu Hospital, Shenzhen, Guangdong 518001, P.R. China
}

Received October 5, 2021; Accepted December 7, 2021

DOI: $10.3892 / \mathrm{mmr} .2022 .12615$

\begin{abstract}
Osteoarthritis (OA), one of the most common joint diseases, is characterized by fibrosis, rhagadia, ulcers and attrition of articular cartilage due to a number of factors. The etiology of OA remains unclear, but its occurrence has been associated with age, obesity, inflammation, trauma and genetic factors. Inflammatory cytokines are crucial for the occurrence and progression of OA. The intra-articular proinflammatory and anti-inflammatory cytokines jointly maintain a dynamic balance, in accordance with the physiological metabolism of articular cartilage. However, dynamic imbalance between proinflammatory and anti-inflammatory cytokines can cause abnormal metabolism in knee articular cartilage, which leads to deformation, loss and abnormal regeneration, and ultimately destroys the normal structure of the knee joint. The ability of articular cartilage to self-repair once damaged is limited, due to its inability to obtain nutrients from blood vessels, nerves and lymphatic vessels, as well as limitations in the extracellular matrix. There are several disadvantages inherent to conventional repair methods, while cartilage tissue engineering (CTE), which combines proinflammatory and anti-inflammatory cytokines, offers a new therapeutic approach for OA. The aim of the present review was to examine the proinflammatory factors implicated in OA, including IL-1 $\beta$, TNF- $\alpha$, IL-6, IL-15, IL-17 and IL-18, as well as the key anti-inflammatory factors reducing OA-related articular
\end{abstract}

Correspondence to: Dr Jianyi Xiong or Dr Weimin Zhu, Department of Sports Medicine, The First Affiliated Hospital of Shenzhen University, Shenzhen Second People's Hospital, 3002 Sungang West Road, Shenzhen, Guangdong 518035, P.R. China E-mail: jianyixiong@126.com

E-mail: szhzwm@email.szu.edu.cn

*Contributed equally

Key words: osteoarthritis, cartilage destruction, inflammatory cytokines, proinflammatory cytokines, anti-inflammatory cytokines, tissue engineering, mesenchymal stem cell damage, including IL-4, insulin-like growth factor and TGF- $\beta$. The predominance of proinflammatory over anti-inflammatory cytokine effects ultimately leads to the development of OA. CTE, which employs mesenchymal stem cells and scaffolding technology, may prevent OA by maintaining the homeostasis of pro- and anti-inflammatory factors.

\section{Contents \\ 1. Introduction \\ 2. Proinflammatory cytokines \\ 3. Anti-inflammatory cytokines \\ 4. CTE \\ 5. Conclusion}

\section{Introduction}

Osteoarthritis (OA), a known degenerative disease, is a chronic joint condition that mainly causes degenerative changes in articular cartilage and secondary osteogenesis, and is characterized by fibrosis, rhagadia, ulcers and attrition of articular cartilage due to a number of factors (1). The main pathological manifestations of OA include, but are not limited to, gradual loss of extracellular matrix (ECM) proteins and proliferation of synovial cells. OA can simultaneously destroy the articular cartilage surface and narrow the articular space. The development of subchondral osteosclerosis and osteophytes may gradually lead to dysfunction of the entire joint. In early-stage OA, the cartilage surface remains intact (2). The first changes occur in the molecular composition of the tissues and the ECM, which are characterized by a transient chondrocyte proliferative response and an increase in ECM protein synthesis, including collagen type II (Col II) and aggrecan (2). With the development of OA, the synthesis of degrading proteases increases, leading to increased catabolic activity and decreased proteoglycan content. Subsequently, $\mathrm{Col}$ II is degraded and its fragments stimulate several proteins associated with the catabolic state, such as MMPs and aggrecanases, members of the a disintegrin and metalloproteinase 
with thrombospondin motifs family (ADAMTSs), which are accompanied by increased expression levels of inflammatory cytokines (IL-1 and TNF- $\alpha$ ), stress and apoptosis markers (caspases-3 and -9 and $\mathrm{Bcl}-2$ ), and transcription factors [runt-related transcription factor 2 (Runx2) and Sox9] (3-5). Changes in articular cartilage composition and structure further stimulate chondrocytes into producing more catabolic factors involved in cartilage degradation. As the proteoglycan and collagen network breaks down, the integrity of the cartilage is disrupted (6). Subsequently, apoptosis of articular chondrocytes occurs, ultimately leading to the complete loss of articular cartilage (Fig. 1) (2,3). Articular chondral injury is often associated with pain, swelling and joint stiffness, or even irreversible damage in certain patients, particularly adolescents, severely compromising their quality of life (7). Articular cartilage tissue is primarily composed of a large amount of ECM with embedded chondrocytes. As the articular cartilage is a special type of connective tissue without blood vessels, lymphatic vessels or nerves, its primary nutrient sources are the synovial fluid in the joint cavity and the blood supply from the subchondral bone. Furthermore, its regenerative capacity is limited. Generally, damage of $4 \mathrm{~cm}$ in diameter cannot be self-repaired (8). Current treatments focus on methods for reducing pain and delaying disease progression. Furthermore, preserving joint function and maintaining the quality of life of the patients has attracted significant attention (1). At present, certain treatments, such as sodium hyaluronate injection, etanercept and infliximab, are used to alleviate symptoms, but with limited efficacy (7). Clinically, methods for repairing chondral injury in the knee joint include microfracture, mosaics, osteochondral grafting and autogenous chondrocyte grafting (8). Although certain techniques have progressed in treating cartilage defects, biological methods for cartilage regeneration are still faced with a major challenge, which lies in the limited regenerative capacity of cartilage tissue (9). It has been reported (10) that a new technological method, percutaneous osmotic therapy, does not cause damage to the digestive system, while it ensures good concentration and utilization of drugs by the target organs. Another type of therapy, intestinal microbial therapy, may contribute to the treatment of systemic inflammation to a certain extent by restoring the intestinal flora (11). Moreover, a previous study reported that the regulation of microRNA (miRNA) expression can inhibit the destruction of articular cartilage caused by OA (12). However, the aforementioned approaches have certain limitations (10). Tissue engineering aims to restore, maintain and improve tissue performance, and it obtains biocompatible and biologically functional tissues to achieve tissue and organ regeneration or repair by combining stem cells and biomaterial scaffolds (10).

Proinflammatory cytokines are endogenous polypeptides that are primarily derived from immune system cells, exert a variety of powerful biological effects and can mediate various immune responses. Currently, the main proinflammatory cytokines involved in OA are IL- $1 \beta$, TNF- $\alpha$, IL-6, IL-15, IL-17 and IL-18 (13). The anti-inflammatory cytokines in OA refer to cytokines that may inhibit the actions of IL-1 $\beta$ and TNF- $\alpha$, and any other cytokine that primarily inhibits the cellular effects of the proinflammatory cytokines in OA (14). At present, the main anti-inflammatory cytokines in OA are IL-4, insulin-like growth factor (IGF), IL-10 and TGF- $\beta(15,16)$. During OA pathogenesis, proinflammatory cytokines release inflammatory mediators by regulating the $\mathrm{NF}-\kappa \mathrm{B}$ and MAPK signaling pathways, which triggers the degeneration, destruction and degradation of articular cartilage (17-19). Anti-inflammatory cytokines can inhibit the actions of proinflammatory cytokines, downregulate the expression levels of MMPs, inhibit inflammatory responses and lysis of articular chondrocytes, promote chondrocyte proteoglycan and collagen synthesis and delay OA progression (20). A possible approach for treating OA is to block a single dominant inflammatory cytokine by employing a similar strategy to target OA inflammatory signaling pathways and maintaining their dynamic balance. Tissue engineering is also critical for maintaining the balance between proinflammatory and anti-inflammatory cytokines (21). Therefore, treating OA with a combination of proinflammatory and anti-inflammatory cytokines, along with tissue engineering, is a trending research topic in OA treatment and it has highlighted a new treatment approach to this disease. The aim of the present study was to therefore review the role of combining proinflammatory and anti-inflammatory cytokines in cartilage tissue engineering (CTE) for the treatment of OA.

\section{Proinflammatory cytokines}

As a group of compounds crucial for the pathogenesis of OA, proinflammatory cytokines may cause the loss of articular cartilage homeostasis via metabolic changes and markedly accelerate joint damage (13). During disease pathogenesis, these compounds affect most cells in the joints and the production of cytokines and other inflammatory compounds and enzymes via intracellular signal transduction pathways. The most important proinflammatory cytokines are IL- $1 \beta, \mathrm{TNF}-\alpha$, IL-6, IL-15, IL-17 and IL-18 (13). How these compounds affect the cells in the joints and the production of cytokines and other inflammatory factors and enzymes is described in this section (Table I).

$I L-1 \beta$. IL- $1 \beta$ is considered to be one of the key cytokines involved in OA pathogenesis. It has been reported to cause inflammatory responses and catabolic effects independently (19). As one of the 11 members of the IL-1 family (22), IL- $1 \beta$ is primarily produced by activated type M1 mononuclear macrophages. In patients with OA, IL-1 $\beta$ levels are elevated in the synovial fluid, synovial membrane (SM), cartilage and subchondral bone layers (23-26). IL-1 $\beta$ binds to its corresponding receptors and promotes the release of proinflammatory cytokines, such as IL-6 and IL-8, by regulating the $\mathrm{NF}-\kappa \mathrm{B}$ and MAPK signaling pathways and increasing the MMP content in the matrices of chondrocytes and fibroblast-like synoviocytes (FLS) (27). MMPs can irreversibly destroy articular cartilage, bone and tendons. Among the MMPs, MMP-1 is primarily expressed by synoviocytes in the joints and MMP-13 by chondrocytes in cartilage. Both these MMPs can degrade collagen, but MMP-13 can also degrade proteoglycan molecules and aggrecans, which indicates MMP-13 serves a dual role in matrix degradation. IL-1 $\beta$ also induces the expression of MMP-2, -3 and -9 in the non-collagenous matrix components of the affected joint (28). Excluding 


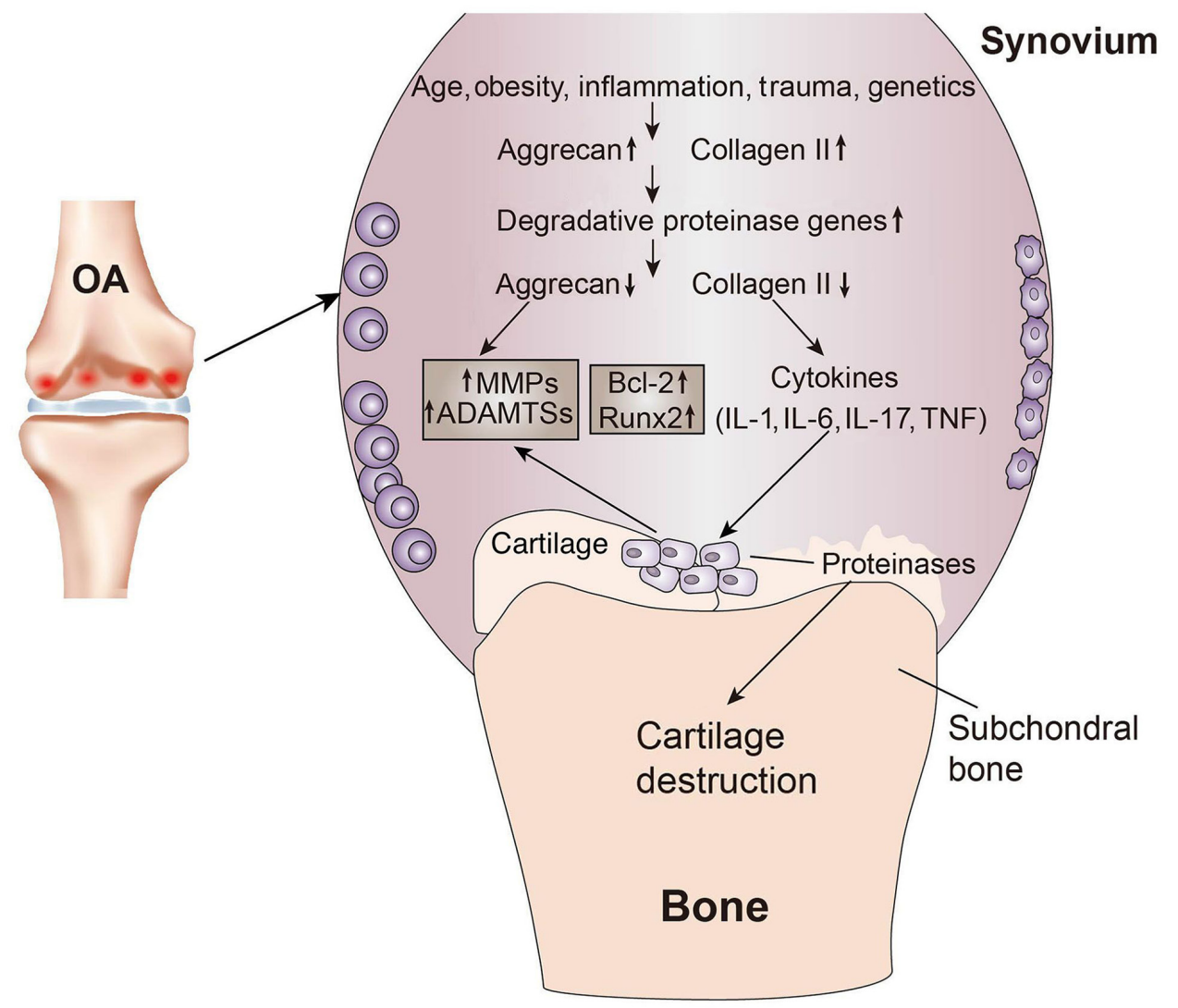

Figure 1. Cartilage changes in OA. Age, obesity, inflammation, trauma and genetics are common causes of OA. In the early stages of OA, chondrocytes proliferate and further extracellular matrix proteins, such as collagen type II, are synthesized. As OA progresses, the gene expression of degradation proteases increases, proteoglycans are gradually lost and, subsequently, with collagen type II degradation, numerous proteins associated with the catabolic state, such as MMPs and ADAMTSs, are produced. With the production of proinflammatory cytokines (IL-1 $\beta$ and TNF- $\alpha$ ) and the increase in the expression of apoptotic markers (Bcl-2 and Runx2) and transcription factors, the proinflammatory cytokines produce more MMPs and ADAMTSs, as well as larger amounts of proteases, which destroy the chondroprotein network, ultimately leading to cartilage destruction. OA, osteoarthritis; ADAMTS, a disintegrin and metalloproteinase with thrombospondin motif; Runx2, runt-related transcription factor 2.

MMP induction, IL-1 $\beta$ also affects ADAMTS production in chondrocytes. ADAMTSs are responsible for the proteolysis of aggregated proteoglycan molecules (29), with ADAMTS-4 being mainly responsible for this effect $(29,30)$. Moreover, the effects of IL-1 $\beta$ on various enzymes and mediators secreted during the pathophysiological process of OA have been observed. Relevant compounds include inducible nitric oxide synthase (iNOS), phospholipase A2, and cyclooxygenase-2 (COX-2) for nitric oxide (NO) production, and prostaglandin $\mathrm{E}$ synthetase 2 for prostaglandin (PG)E2 production $(31,32)$. NO, as a free radical, promotes the pathological progression of $\mathrm{OA}$ by inhibiting chondrocyte proliferation and inducing chondrocyte apoptosis (33). Its catabolism in OA articular cartilage is as follows: i) Inhibits Col II synthesis; ii) inhibits proteoglycan synthesis; iii) inhibits IL-1 receptor antagonist (RA) production; iv) interferes with integrin signals; v) induces chondrocyte apoptosis; vi) stimulates MMP production and activation; and vii) inactivates tissue inhibitor of metalloproteinases (TIMP) (34). PGE2, as one of the metabolites of arachidonic acid, has the following actions: i) Absorbs subchondral bone; ii) affects bone and cartilage anabolism; and iii) prevents the biochemical synthesis of proteoglycans, leading to Col II destruction and articular cartilage degeneration (35). Its catabolism in cartilage is primarily achieved by activating MMPs. Furthermore, IL-1 $\beta$ stimulates reactive oxygen species production, for example, the formation of peroxides and hydroxylated radicals, and therefore directly damages articular cartilage during disease progression. In the affected joints, the intensification of this process is reported to be associated with decreased oxidase expression (36).

In summary, IL-1 $\beta$ binding to the IL-1R in SM cells, activates transcription factors via the $\mathrm{NF}-\kappa \mathrm{B}$ and MAPK signaling pathways to regulate inflammatory responses, resulting in the production of inflammatory mediators in SM cells, such as MMPs, COX-2, PGE2, NO and other catabolic factors, which may accelerate cartilage degeneration. Therefore, blocking the aforementioned signaling pathways mediated by inflammatory cytokines may be a potential novel therapeutic strategy for treating OA.

$T N F-\alpha$. Evidence suggests that TNF- $\alpha$, one of the 19 ligands in the TNF superfamily, is involved in the pathogenesis and progression of OA (37). TNF- $\alpha$ is also produced by activated type M1 mononuclear macrophages. It may kill or inhibit tumor cells and promote the phagocytosis of neutrophils (37). Its original form is a type-II homotrimer transmembrane protein and under the action of TNF convertase/ADAMTS17, free TNF- $\alpha$ is produced (38). This cytokine binds to two membrane receptor isotypes, TNF-R1 (also known as p55, CD120a and TNF-R super family member 1a) and TNF-R2 
Table I. Potential roles and origins of proinflammatory cytokines.

\begin{tabular}{|c|c|c|c|}
\hline Cytokine & Source & Role & (Refs.) \\
\hline IL-1 $\beta$ & $\begin{array}{l}\text { Macrophages, fibroblasts, chondrocytes, } \\
\text { osteoblasts and osteoclasts }\end{array}$ & $\begin{array}{l}\text { Potent inducer of cartilage degradation and bone } \\
\text { resorption }\end{array}$ & $(16,17,20)$ \\
\hline TNF- $\alpha$ & Macrophages, fibroblasts and chondrocytes & Similar activity profile to IL-1, but less potent & $(30,39,40,44)$ \\
\hline IL-6 & $\begin{array}{l}\text { Macrophages, fibroblasts, chondrocytes, } \\
\text { osteoblasts and osteoclasts }\end{array}$ & $\begin{array}{l}\text { IL- } 6 \text { with Il- } 1 \beta \text { and TNF- } \alpha \text { have a synergistic } \\
\text { effect, which may promote ECM degradation of } \\
\text { cartilage, leading to changes in subchondral bone }\end{array}$ & $(57,59,61)$ \\
\hline IL-15 & $\begin{array}{l}\text { Macrophages, fibroblasts and epidermal } \\
\text { cells }\end{array}$ & $\begin{array}{l}\text { Further activates various cytokines, including } \\
\text { TNF- } \alpha \text {, IL-1, IL- } 6 \text { and IL- } 17\end{array}$ & $(62,69)$ \\
\hline IL-17 & Macrophages & $\begin{array}{l}\text { Promotes the release of various proinflammatory } \\
\text { cytokines and compounds, including, IL-1 } \beta \text {, } \\
\text { TNF- } \alpha, \text { NO and PGE } 2 \text {, as well as MMPs }\end{array}$ & $(71,72,77)$ \\
\hline IL-18 & Macrophages and dendritic epithelial cells & $\begin{array}{l}\text { Recruits monocytes and } \mathrm{T} \text { lymphocytes to induce } \\
\text { IFN- } \gamma \text { production and inhibit angiogenesis }\end{array}$ & $(81,82,84)$ \\
\hline
\end{tabular}

ECM, extracellular matrix; NO, nitric oxide; PGE2, prostaglandin E2.

(also known as p75, CD120b and TNF-R superfamily member $1 b)$ on the surface of nearly all nucleated cells $(39,40)$. TNF- $\alpha$ binding to TNF-R1 leads to the interaction of the TNFR1-associated death domain (DD) protein adaptor protein with other adaptor proteins, such as TNF-R associated factor 2, cellular inhibitor of apoptosis protein (c-IAP)1, c-IAP2 and receptor-interacting protein (RIP)1 (41-43). The creation of the complex is followed by the ubiquitination of the RIP1 protein, which also binds to TGF $\beta$-activated kinase (TAK)1, TAK1-binding protein (TAB)1 and TAB2, leading to phosphorylation of the IKK complex and ultimately the activation of $\mathrm{NF}-\kappa \mathrm{B}$, one of the most important transcriptional signaling pathways in OA $(44,45)$. TNF- $\alpha$ exerts its effects on chondrocytes similar to IL- $1 \beta$, including stimulating stromal degradation proteases, NO and PGE2 production, as well as inhibiting cartilage matrix synthesis (46-50). However, despite their similar effects, IL- $1 \beta$ is 100 - to 1,000 -fold more potent compared with TNF- $\alpha(51,52)$. The activity of these two cytokines may produce a strong synergistic effect. For example, intra-articular injection of recombinant IL-1 alone in rats, mice and rabbits stimulates articular cartilage destruction. Furthermore, when TNF- $\alpha$ and IL-1 are injected together, cartilage damage may be far more severe compared with that caused by either cytokine alone (53-55). Moreover, the effects of TNF- $\alpha$ mediated via the PI3K/Akt axis may increase the expression levels of cadherin-11, and this expression in FLS exhibits a positive correlation with the severity of synovitis and cartilage destruction (56). In an animal experiment, Liu et al (57) demonstrated that TNF- $\alpha$ stimulation increases cadherin-11 expression at the mRNA and protein levels in OA FLS, whereby it also promotes the phosphorylation of Akt. The intra-articular injection of anti-cadherin-11 antibody decreases cadherin-11 expression in the SM and alleviates synovitis and cartilage damage. These results indicated that TNF- $\alpha$ can induce cadherin-11 expression and this protein may cause synovitis and cartilage injury. Furthermore, cartilage injury may be treated by inhibiting cadherin-11 expression, which may be achieved by suppressing TNF- $\alpha$ expression (57).
In conclusion, free TNF- $\alpha$ binds to the corresponding receptor and activates transcription factors via the $\mathrm{NF}-\kappa \mathrm{B}$ signaling pathway to produce an inflammatory response, similar to but weaker than IL-1 $\beta$. These two cytokines can exert a synergistic effect and further enhance the inflammatory response. Furthermore, the effects of TNF- $\alpha$ can also be mediated via the PI3K/Akt axis, which can increase the expression of cadherin-11 in FLS, resulting in an increased degree of synovitis and cartilage destruction.

Unlike the aforementioned proinflammatory cytokines, in OA pathogenesis, proinflammatory cytokines, including IL-6, IL-15, IL-17 and IL-18, synergistically promote the development of inflammation, upregulate the expression levels of MMPs, promote the degradation of cartilage ECM and, eventually, destroy the normal structure of the knee joint (58-62).

$I L-6$. IL-6 is a cytokine with numerous biological functions that is produced by monocytic macrophages, endothelial cells and lymphoid cells, and is crucial in the immune response, acute phase response and hematopoietic regulation (63). Healthy cartilage tissue may produce small quantities of IL-6, but a previous study has reported abnormally elevated IL-6 levels in the synovial fluid or serum in patients with OA (16). Highly expressed IL-6 can induce MMP-3 and MMP-13 production and promote cartilage ECM degradation, which therefore destroys the normal joint structure (64). Furthermore, IL-6 is considered to be the key cytokine that causes changes in the subchondral bone layer, including promoting inflammation in synovial tissue, increasing cartilage permeability, accelerating osteoclast formation, as well as causing cartilage absorption, degradation and destruction, ultimately leading to enhanced FLS proliferation $(65,66)$. Moreover, studies have demonstrated a synergistic effect of IL- 6 with IL- $1 \beta$ and TNF- $\alpha(65,67)$. IL-6 itself has no direct effect on the synthesis of protease, PGE, or matrix proteins, but it may stimulate TIMP synthesis, thereby exerting a protective effect on cartilage (68). Proinflammatory cytokines can also activate the MAPK signaling pathway in synoviocytes and chondrocytes, which initiates a signaling 
cascade, leading to the release of the inflammatory mediator IL-6 and damage of articular cartilage (66).

$I L-15$. IL-15 is a cytokine with a wide range of biological functions that is produced by numerous types of cells, including activated monocytes, epidermal cells and FLS. IL-15 is a key component of the body's immune response (69). IL-15 is a glycoprotein that exists in the form of four interconnected $\alpha$-helices and has a mass of $14-15 \mathrm{kDa}(70,71)$. It acts primarily via stimulating the differentiation and proliferation of T cells and natural killer (NK) cells (72). Moreover, it is one of the most well-documented cytokines involved in the pathogenesis of rheumatoid arthritis (RA) $(73,74)$. A previous study reported that the levels of IL-15 and MMP-7 in the synovial fluid of patients with OA were significantly increased, and higher levels were associated with more severe OA manifestations, indicating an association between IL-15 and OA (75). Furthermore, IL-15 can upregulate MMP-1 expression levels and promote the degradation of cartilage in the ECM (61). IL-15 can also induce the activation of mononuclear macrophages and neutrophils, which secrete a variety of proinflammatory cytokines, such as TNF- $\alpha$, IL-1, IL-6 and IL-17 (76). Moreover, highly expressed proinflammatory cytokines, such as TNF- $\alpha$ and IL-1 $\beta$, may in turn promote IL-15 release (76). The proinflammatory cytokines interact to promote inflammation and eventually destroy the normal cartilage structure, which causes OA (77). Furthermore, a previous study reported that increased serum IL-15 levels are be correlated with pain perception and the severity of lesions on x-ray images (78). IL-15 may also be involved in bone destruction in RA and can be used as one of the indicators for monitoring the damage of articular cartilage in patients with RA (61).

$I L-17$. IL-17 is a proinflammatory cytokine produced by $\mathrm{CD} 4^{+}$memory $\mathrm{T}$ lymphocytes and monocytes. It consists of 6 members (IL-17A-F), which interact via five types of receptors (IL-17RA-E) $(79,80)$. IL-17 has a variety of biological effects. Studies have reported that it can cause cartilage destruction primarily via stimulating FLS, chondrocytes and macrophages to release enzymes that degrade cartilage (81-84). Another study indicated that IL-17 also serves an important role in the pathogenesis of OA and in OA-related pain (85). IL-17 causes inflammatory cells to release various proinflammatory factors and compounds, including IL- $1 \beta$, TNF- $\alpha$, NO and PGE2, as well as MMPs, which may promote the development of OA and accelerate the destruction of articular cartilage. Furthermore, this process is associated with the release of proinflammatory cytokines, such as IL-7, IL-6 and IL-23 (86). The effect of IL-17 on the secretion of VEGF by chondrocytes and FLS is also a known characteristic and it is conducive to the overdevelopment of the vascular network in the synovium, which leads to hypertrophy $(87,88)$. It has also been reported (89) that IL-17A stimulation can alter chondrocyte morphology, inhibiting the activity of chondrocytes and producing a series of inflammatory responses, which may ultimately lead to chondrocyte apoptosis.

$I L-18$. IL-18 is produced by activated macrophages, dendritic cells and epithelial cells. It is a precursor of pro-IL-18, consists of 192 amino acid residues, and is converted into biologically active forms following activation by caspase- 1 or protease $3(90,91)$. It is primarily involved in mediating tissue inflammation and it is also crucial for regulating immune networks. While mediating tissue inflammation, IL-18 is associated with TNF- $\alpha$ and comes into direct contact with T lymphocytes in the synovial fluid (92) and therefore stimulates monocytes to increase the release of TNF- $\alpha$ and induces the production of IFN- $\gamma$. The latter can significantly stimulate the release of IL-6, NO and PGE2 in the synovial fluid, which are inflammatory factors involved in the occurrence of OA (93). Furthermore, IL-18 can increase the concentration of cartilage-degrading enzymes by inducing $\mathrm{TNF}-\alpha$, which inhibits the synthesis of proteoglycans, aggrecan and Col II, promotes their degradation and, ultimately, inhibits the proliferation of chondrocytes, accelerating their apoptosis and destroying articular cartilage (94-96). IL-18 also affects the chondrocytes in patients with OA. IL-18 induces chondrocytes to exhibit typical morphological changes of apoptotic cells via inducing the upregulation of IL-18R $\alpha$ expression on the chondrocyte surface and upregulating the expression of MMP-1, MMP-3 and MMP-13 (97).

In summary, proinflammatory cytokines exert a primarily destructive effect on articular cartilage. This is a multi-layered effect, involving not only the induction of chondrocyte senescence and apoptosis, but also a reduction in the synthesis of key components of the ECM, such as proteoglycans and Col II. Furthermore, inflammatory cytokines may promote the synthesis and release of several proteolytic enzymes that break down articular cartilage, including MMPs and ADAMTSs. Therefore, OA may be treated at the molecular level via inhibition of a single dominant proinflammatory cytokine, which may improve the efficacy of OA treatment and the efficiency of cartilage repair by improving both the internal and external factors of medication and rehabilitation.

\section{Anti-inflammatory cytokines}

Anti-inflammatory cytokines in OA include cytokines that inhibit at least one of the main proinflammatory cytokines responsible for the development and progression of OA, such as IL-1 $\beta$ and TNF- $\alpha$. At present, the main anti-inflammatory cytokines in OA are considered to be IL-4, IGF, IL-10 and TGF- $\beta$ (20). In the pathogenesis of OA, anti-inflammatory cytokines may inhibit the action of proinflammatory cytokines, downregulate the expression levels of MMPs, inhibit the inflammatory response and lysis of articular chondrocytes, promote the synthesis of chondrocyte proteoglycans and $\mathrm{Col}$ II and delay the progression of OA (20). The roles of these cytokines are discussed below (Table II).

$I L-4$. IL-4 is a protein composed of 129 amino acids in the form of four interlinked $\alpha$-helices stabilized by three disulfide bonds (98-100). IL-4 is a ligand (101) and as a cytokine produced by activated $\mathrm{T}$ cells, it can regulate a variety of immune cells, including B cells, T cells, mast cells, M2 macrophages and hematopoietic cells $(83,102)$. Previous studies have demonstrated that IL-4 exerts a significant inhibitory effect on the expression and release of proinflammatory cytokines and blocks or inhibits monocyte-derived cytokines, including 
Table II. Potential roles and origins of anti-inflammatory cytokines.

\begin{tabular}{|c|c|c|c|}
\hline Cytokine & Source & Role & (Refs.) \\
\hline IL-4 & Macrophages and TH2 cells & $\begin{array}{l}\text { Reduces the secretion of TGF- } \beta \text { receptors in the body by } \\
\text { regulating IL- } 1, \mathrm{IL}-6 \text {, and TNF secretion }\end{array}$ & $(93-98)$ \\
\hline IGF & $\begin{array}{l}\text { Macrophages, fibroblasts, } \\
\text { chondrocytes and osteoblasts }\end{array}$ & $\begin{array}{l}\text { Stimulates the production of cartilage matrix components. } \\
\text { Also thought to stimulate osteoclast cell lineage replication }\end{array}$ & $(106,108-110)$ \\
\hline IL-10 & Macrophages & $\begin{array}{l}\text { Inhibits the secretion of various proinflammatory cytokines } \\
\text { and compounds, including, IL- } 6, \mathrm{TNF}-\alpha \text { and NO, and } \\
\text { promotes Col II synthesis }\end{array}$ & $(119-122)$ \\
\hline TGF- $\beta$ & $\begin{array}{l}\text { Macrophages, fibroblasts, } \\
\text { chondrocytes, osteoblasts } \\
\text { and osteoclasts }\end{array}$ & $\begin{array}{l}\text { Stimulates the production of cartilage matrix components. } \\
\text { Promotes chondrogenic differentiation of MSCs }\end{array}$ & $(126,129-131)$ \\
\hline
\end{tabular}

TH2, T helper 2 cells; NO, nitric oxide; Col II, collagen type II; MSC, mesenchymal stem cell.

IL-1, TNF- $\alpha$, IL-6, IL- 8 and the macrophage inflammatory protein-1a (103-106). It has also been reported to inhibit macrophage cytotoxic activity, kill parasites and produce macrophage-derived NO (107). Furthermore, it can stimulate IL-1RA synthesis (108). IL-4 also exerts a strong protective effect on cartilage and numerous studies have demonstrated that IL-4 can induce the transcriptional regulator CITED2, which can reduce variations in proteoglycan production during the course of OA and prevent proteoglycan degradation in articular cartilage by inhibiting MMP-13 (109-111). A study also demonstrated that the protective effect of IL-4 on cartilage is attributed to NO inhibition. In a previous study (112), in which recombinant rat IL-4 was injected into OA rats, the results indicated that the recombinant rat IL-4 downregulated the expression of iNOS mRNA and NO production in chondrocytes induced by cyclic tensile stress. Therefore, a limited but significant improvement in cartilage destruction may be achieved, loss of aggrecan may be prevented and the number of nitrotyrosine-positive chondrocytes may be reduced. These effects are not dose-dependent and therefore OA-induced cartilage destruction may be treated by IL-4 via inhibition of NO production by chondrocytes (113). Furthermore, IL-4 can promote macrophage transformation into the M2 phenotype by promoting an immunomodulatory microenvironment, effectively removing the proinflammatory debris of articular cartilage and maintaining the stability of osteoclasts to maintain the health of the articular cartilage (114). IL-4 can also inhibit the expression of ADAMTS-4 and -5 , delay ECM degradation and promote the synthesis of chondrocyte proteoglycan and Col II in articular cartilage (27).

In conclusion, IL-4 can inhibit inflammation by decreasing the expression and release of inflammatory cytokines and promoting the expression of IL-1RA. IL-4 serves a chondroprotective role at the gene and protein levels by decreasing the expression of NO, MMPs and ADAMTSs.

$I G F$. IGF is a peptide hormone that exerts the physiological effect of growth stimulation. IGF regulates the synthesis of glycogen and proteins, cell proliferation, differentiation and apoptosis, and induces chondrogenesis (115). The IGF network is composed of IGF-1, IGF-2 and their receptors
(IGF-1R and IGF-2R), as well as six IGF-binding proteins. As one of the main IGF factors, IGF-1 can be synthesized by a variety of cell types (115). It acts on targeted organs via endocrine, paracrine or secretory actions, regulates glycogen and protein synthesis and decomposition, and participates in the processes of metabolism, cell proliferation, differentiation and apoptosis, indicating that it serves an important role in repairing numerous systems in the body (116).

$\mathrm{OA}$ is a skeletal motor system disease characterized by cartilage degeneration. Chondrocytes, as the only cells in cartilage, can proliferate under the influence of IGF-1, and synthesize cartilage matrix proteoglycans and matrix collagen. Physiologically, in infants, children and adolescents, IGF-1 promotes linear bone growth by stimulating chondrocyte proliferation and shaping (117). In adults, IGF-1 inhibits chondrocyte aging and death by stimulating chondrocytes to synthesize matrix proteins, suggesting that IGF-1 may be used to treat OA $(118,119)$. In an in vitro test, Yaeger et al (120) demonstrated that after bovine articular chondrocytes were treated with IGF-1, the collagen content was significantly increased when compared with the untreated control. Furthermore, Madry et al (121) treated osteochondral defects in a rabbit model by using chondrocytes transfected with a plasmid vector containing human IGF-1 in a hydrogel. This study confirmed that at 14 weeks post-treatment, the test group was significantly superior to the control group in terms of histological grading (defect filling, integration and cell morphology). In an equine model, Fortier et al (122) reported that adding IGF-1 to the chondrocyte-fibrin complex enhanced cartilage formation in cartilage defects, and 8 months after treatment compared with the control group treated by chondrocyte-fibrin complex alone, the severe defects in the repaired tissue were filled, with the mean Col II content exhibiting a significant increase. These results suggested that in the co-culture of IGF-1 and chondrocytes, chondrocytes are regulated by IGF-1, which promotes not only chondrocyte division and proliferation, but also cell function and synthesis of proteoglycans and Col II. IGF-1 also exhibited a positive effect when combined with other growth factors/cytokines. Certain studies reported that, when IGF-1 and TGF- $\beta$ were combined, the production of cartilage matrix components 
(such as proteoglycans) increased, the Col II and aggrecan gene expression levels in chondrocytes were upregulated and the chondrogenic differentiation of mesenchymal stem cells (MSCs) was enhanced $(123,124)$. Morisset et al (125) injected adenovirus-transfected IGF-1 and IL-IRa into the joints of 12 horses with minor fractures in the carpal bones caused by full-thickness cartilage defects. It was discovered that the cartilage defects were completely restored. The combination of IGF-1 and IL-1RA further reduced cartilage degeneration when compared with IL-1RA alone. Therefore, the combination of IGF-1 and IL-1 Ra could potentially reduce or even reverse the loss of cartilage in OA, thus improving the effects of OA treatment. Furthermore, IGF-1 may also inhibit chondrocyte apoptosis. An in vitro chondrocyte culture demonstrated that IGF-1 reversed the inhibitory effects of dexamethasone on chondrocyte proliferation and prevented the apoptosis of chondrocytes caused by collagenase (126). Moreover, IGF-1 may prevent chondrocyte apoptosis via the P13K and MAPK signaling pathways (127).

$I L-10$. IL-10 is a well-known anti-inflammatory and immunomodulatory cytokine that is primarily released by cells of the immune system, including monocytes, macrophages, T cells, NK cells and B cells (128). IL-10 may also be produced by a few connective tissue cell types, including chondrocytes, and is involved in processes such as ECM remodeling in connective tissues (128). IL-10 can inhibit the synthesis and secretion of related proinflammatory cytokines, such as IL-6, thus regulating inflammatory immunity $(129,130)$. IL-10 can also reduce iNOS2 expression, thereby reducing the release of $\mathrm{NO}$, interfering with the oxidative stress matrix and delaying joint degeneration (131). Furthermore, IL-10 prevents early apoptosis induced by TNF- $\alpha$ by reducing the expression of TNF- $\alpha$-induced matrix-degrading enzymes, the release of glycosaminoglycans and the formation of G1 fragment of the proteoglycan aggrecan (132). IL-10 can also activate the SMAD1/SMAD5/SMAD8 and ERK1/2/MAPK signaling pathways and induce the expression of bone morphogenetic protein (BMP)-2 and BMP-6. As members of the TGF- $\beta$ family, BMP proteins serve a crucial role in chondrogenesis (105). Through their signaling pathways, they affect numerous genes and proteins regulating chondrocyte mesenchymal cell transformation, such as NK3 homeobox 2/Sox9, Sox 5 and Sox6 $(133,134)$.

TGF- $\beta$. The TGF- $\beta$ superfamily consists of $>30$ structurally-related members, including TGF- $\beta 1,2$ and 3 (135). TGF- $\beta 1$ is a multifunctional growth factor that regulates a wide range of biological processes, including cell proliferation, survival, differentiation, migration and ECM generation $(136,137)$. TGF- $\beta 1$ signaling affects MSCs and their progenitors. Studies have demonstrated that active TGF- $\beta 1$ released by osteoclasts during bone resorption may guide the migration of bone marrow MSCs (BMSCs) to form new cartilage at resorption sites, induce Sox-9 expression in BMSCs and increase the generation of ECM (138-140). Therefore, TGF- $\beta 1$, as a soluble factor, contributes to BMSC differentiation. Furthermore, TGF- $\beta 1$ is critical for maintaining homeostasis between subchondral bone and articular cartilage (141). TGF- $\beta 1$ is a well-documented potent chondroblast factor that may stimulate chondrocytes to synthesize and secrete proteoglycans and Col II (141). One of the first TGF- $\beta 1$ activities to be discovered was the in vitro induction of primitive rat mesenchymal cells to promote chondrogenesis $(142,143)$. Subsequently, TGF- $\beta 1$-induced chondroblasts have been observed in rabbit chondrocyte cultures (144), chicken mesenchymal cells, as well as bovine nose and articular chondrocyte cultures $(145,146)$.

With a biological function similar to that of TGF- $\beta 1$, TGF- $\beta 2$ may regulate cartilage and osteogenic differentiation (147). It has been demonstrated that following TGF- $\beta 2$ treatment of dedifferentiated chondrocytes, the cells re-expressed glucosamine and Col II and the chondrogenic phenotype was therefore restored. It has also been reported that precursor cells isolated from the perichondrium show the potential for chondrogenic differentiation after being cultured in a medium containing TGF- $\beta 2$ and IGF- 1 before producing a cartilage matrix (148).

As another important member of the TGF family of cytokines, TGF- $\beta 3$ can promote the proliferation and differentiation of chondrocytes, accelerate the formation of ECM, inhibit the activity of various inflammatory mediators, including IL-1, MMPs and TNF- $\alpha$, and reduce the immune response of the body, thus serving a crucial role in wound healing, particularly in cartilage growth and reconstruction (149). TGF- $\beta 3$ is expressed in a number of different types of cells and tissues in the body, including the placenta, adipose tissue, embryonic tissues, liver, bone and bone marrow, as well as in tumors, and is secreted extracellularly via autocrine and paracrine routes. TGF- $\beta 3$ is an extracellular ligand and its effects are mediated by binding to serine/threonine kinase receptors on the cell surface. TGF- $\beta 3$ activates the transcription factors SMAD2/SMAD3 via the intracellular SMAD signaling pathway, and activates and binds to SMAD4, forming a complex, which translocates to the nucleus and regulates the transcriptional expression of the downstream TGF- $\beta$ gene and therefore its biological function $(150,151)$. Furthermore, it can inhibit inflammatory responses and promote TIMP expression (150). It has also been reported that the ability of TGF- $\beta 2$ and TGF- $\beta 3$ to induce chondrogenic differentiation of MSCs may be superior to that of TGF- $\beta 1$ (151).

In summary, the main effects of anti-inflammatory cytokines involve inhibiting the synthesis of proinflammatory cytokines, particularly IL- $1 \beta$ and TNF- $\alpha$. The main effects of anti-inflammatory cytokines include increasing the synthesis of proteins and polysaccharides, inhibiting chondrocyte apoptosis and reducing the synthesis and secretion of MMPs and ADAMTSs. Anti-inflammatory cytokines can also act on target cells to increase matrix degradation products dependent on cytokine functions. The cytokines that inhibit or antagonize the activity of catabolic cytokines are classified as anti-catabolic or inhibitory cytokines (IL-4 and IL-10), and the cytokines that promote chondrocyte proliferation and differentiation are classified as anabolic cytokines (IGF and TGF- $\beta$ ). The effects of catabolic cytokines should be viewed as inhibitory on proinflammatory cytokines rather than having direct protective effects on cartilage. In healthy joints, anti-inflammatory cytokines do not exert significant anabolic effects but may have sufficient biochemical dominance against proinflammatory cytokines. The effects of anti-inflammatory cytokines may become apparent in the joints affected by 
disease only in the presence of inflammatory mediators. Anabolic cytokines mainly exert a protective effect on chondrocytes and they also inhibit proinflammatory cytokines. Maintaining a dynamic balance between proinflammatory and anti-inflammatory cytokines is crucial for OA treatment. Thus, the roles of proinflammatory and anti-inflammatory cytokines in OA must be further elucidated and efforts must be made to design an appropriate treatment method that may prevent or delay OA progression.

\section{CTE}

CTE technology is used to culture and amplify cartilage seed cells in vitro, and to implant them on high-density scaffolds with good biocompatibility and degradability, thus forming tissue-engineered cartilage using regulatory factors. There are three main conditions for constructing tissue-engineered cartilage: i) A sufficient quantity of functioning seed cells; ii) a suitable cellular scaffold; and iii) cytokines that can regulate cell proliferation and maintain the phenotypic characteristics of the cells $(152,153)$. Directed differentiation of chondrocytes may be regulated by controlling relevant environmental factors, therefore producing the desired cells. Cytokines can significantly promote cell differentiation in chondrocytes, which induces the relevant functions. Multiple cytokines jointly stimulate the entire seed cell differentiation process to chondrocytes (154). It has been reported (153) that tissue engineering can be used in the repair of the nose, trachea or auricle, and certain patients have undergone successful repair of nasal alar lobe defects via CTE. The development of CTE technology is promising and it may enable successful cartilage repair. Regulating proinflammatory and anti-inflammatory cytokines and maintaining their balance during OA treatment has been proven to be a useful treatment strategy (155). CTE technology is crucial for regulating anti-inflammatory and proinflammatory cytokines and maintaining the balance between the two, which may provide a new approach to OA treatment. How CTE technology can be used to treat OA by regulating proinflammatory and anti-inflammatory cytokines is discussed in this section.

MSCs. MSCs are adult stem cells with multipotent differentiation potential and the ability to self-renew, which were first isolated from the bone marrow. MSCs are ideal seed cells for tissue engineering, as they can differentiate into adipocytes, osteoblasts and chondrocytes and are capable of transdermal differentiation (156). A number of studies have reported that MSCs can be used to repair and regenerate myocardial tissue, damaged bone tissue, cartilage tissue and tendons (157-159). The main mode of action for MSCs is based on paracrine mechanisms (160). Exosomes are important carriers of paracrine delivery factors promoting cell-to-cell conduction. As the smallest known bilayer nanovesicles, exosomes are rich in biologically active molecules, such as mRNAs, microRNAs (miRNAs) and proteins, and they are involved in communication between cells (155). All cells secrete exosomes, which are present in bodily fluids, including blood, saliva, amniotic fluid, ascitic and cerebrospinal fluid (161). During early-stage OA, exosomes in the articular cavity mediate anti-inflammatory cytokines and miRNAs for cartilage repair. However, in the intermediate or advanced stages of the disease, they can induce related proinflammatory cytokine and proinflammatory miRNA production to accelerate relevant pathological changes (155). Therefore, exosomes can regulate the expression of proinflammatory and anti-inflammatory cytokines, which can therefore alter the pathological and/or physiological processes implicated in certain diseases. A previous study demonstrated (161) that the exosomes of adipose MSCs (ADMSCs) can reduce the production of proinflammatory cytokines, including TNF- $\alpha$, IL-6 and IL-10, in OA chondrocytes. Furthermore, following the downregulation of COX-2 and PGE1 expression levels, PGE2 production is decreased (155). Moreover, ADMSC exosomes inhibit the activation of the $\mathrm{NF}-\kappa \mathrm{B}$ signaling pathway, serving an anti-inflammatory role (33). It has also been demonstrated that BMSC exosomes inhibit chondrocyte destruction via inflammatory mediators and TNF- $\alpha$-induced inflammation. The chondrocytes treated by exosomes exhibit significantly decreased levels of COX-2 expression and inflammatory mediators, including IL-1, IL-6, IL-8 and IL-1 $(162,163)$. As well as reducing the inflammatory response of chondrocytes, MSC exosomes can also regulate chondrocyte apoptosis and macrophage activity. For example, Cosenza et al (163) investigated the protective effect of MSC-derived exosomes in cartilage degradation in OA rats. The results demonstrated that MSC-derived exosomes significantly reduced IL-1 $\beta$-induced chondrocyte apoptosis. Furthermore, MSC-derived exosomes reduce the expression levels of CD86, major histocompatibility complex II and CD40 in F4/80 macrophages. MSCs co-cultured with macrophages can also reduce type M1 macrophages and promote their transformation into type M2 macrophages (Fig. 2) (164). In a collagenase-induced OA model, intra-articular injections of MSC-derived exosomes significantly increase cartilage volume, surface volume ratio and thickness (165). Therefore, exosomes can alleviate inflammation and repair cartilage by mediating the effects of proinflammatory and anti-inflammatory cytokines.

As important mediators of intercellular communication, exosomes are involved in the occurrence of joint diseases. Although exosomes may accelerate articular cartilage destruction and promote the progression of joint diseases via signaling pathways, they have also shown great potential in OA pathogenesis and treatment. The exosomes released by MSCs can promote anti-inflammatory cytokine secretion, delay joint disease progression and repair damaged joints by inhibiting the secretion of proinflammatory cytokines. Further research on these exosomes may provide novel ideas for treating OA. Although studies on exosomes have reported certain exciting findings, there remain certain limitations, such as the high manufacturing costs, difficulties in isolation and purification, and insufficient efficacy and safety evaluation $(163,166,167)$. Therefore, exosomes still require in-depth studies to further explore their therapeutic potential.

Scaffolding technology. The CTE bionic scaffold technology offers numerous possibilities for cartilage repair and regeneration. Guided by cytokines, autologous seed cells (stem cells/progenitor cells) can be recruited from the injured site to repair the injured bone and cartilage using scaffold materials to regulate their own microenvironment (168). Therefore, 


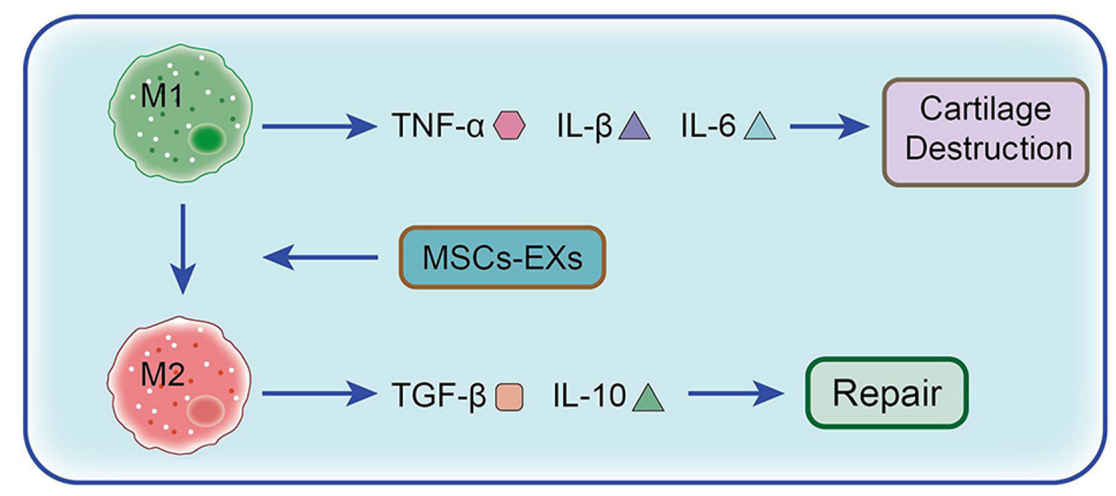

Figure 2. Role and mechanism of MSCs in the treatment of OA. When stimulated by stress, surgery and/or trauma, M1 macrophages, under the induction of IFN and lipopolysaccharide, produce the proinflammatory cytokines TNF- $\alpha$, IL-1 $\beta$ and IL- 6 , consequently promoting cartilage damage. However M2 macrophages, under the induction of IL-13 and IL-3, produce the anti-inflammatory cytokines IL- 10 and TGF- $\beta 1$ to promote cartilage repair. MSCs promote the phenotypic transformation of synovial macrophages from M1 to M2 via exosomes, which significantly reduces the levels of the proinflammatory cytokines IL-1 $\beta$, IL- 6 and TNF- $\alpha$, while the significant increase in anti-inflammatory cytokine IL-10 and reduction in inflammation enable cartilage repair. OA, osteoarthritis; MSC, mesenchymal stem cell; MSCs-EX, exosome.

the exogenous seed cells required by traditional tissue engineering technology may become unnecessary, and certain limitations, such as the long duration for in vitro reproduction of exogenous seed cells and potential immune system rejection, may be avoided (163). The duration for treatment may be significantly shortened and the treatment failure rate may be reduced. Therefore, when treating bone and cartilage injuries, am effective therapeutic may be produced $(168,169)$. There are currently two main categories of scaffold materials commonly used in CTE: i) Synthetic polymer materials, such as polyglycolic acid, polylactic acid (and their copolymer, poly lactic-co-glycolic acid) and polyvinyl oxide; and ii) natural polymer materials, such as collagen, chitosan, alginate, hyaluronic acid, fibrin and agarose. According to their morphology, these can be divided into prefabricated 3D porous scaffolds and hydrogel materials (170). The aforementioned materials can endogenously regulate proinflammatory and anti-inflammatory cytokines and can be used to treat OA by controlling the microenvironment in vivo. Jiang et al (171) previously prepared a composite electrospinning nanofiber composed of cartilage matrix components (collagen or chondroitin sulfate) and poly( $\varepsilon$-caprolactone)-polytetrahydrofuran. Moreover, experimental results (137) have demonstrated that this nanofiber can regulate the TNF and hypoxia-inducible factor-1 signaling pathways by addition of chondroitin sulfate or collagen, which upregulates BMP2 and IGF-1 and promotes cartilage formation. Fasolino et al (172) proposed a bionic chitosan-based scaffold and experimentally demonstrated that the biologically activated scaffold could inhibit the synthesis of inflammatory mediators, such as IL-1 $\beta$, reduce oxidative stress metabolites and promote the production of the anti-inflammatory marker IL-10 in MSCs. The biologically activated scaffold also exhibited anti-inflammatory activity in an in vitro co-culture. Therefore the damaged cartilage microenvironment in vivo could be efficiently simulated by it. Results have also demonstrated that at the molecular level the cartilage scaffolds can regulate the microenvironment in the joints, promote the secretion of anti-inflammatory cytokines and inhibit the secretion of proinflammatory cytokines, which promotes cartilage repair. Bhardwaj et al (173) co-cultured articular chondrocytes and ADMSCs in a 3D scaffold based on silk fibroin proteins. Compared with the single control group, the co-culture group exhibited significant increases in TGF- $\beta 1$ and IL-10 levels, thus upregulating the expression of the bone formation markers aggrecan, Sox-9 and Col II, while the expression levels of the hypertrophy gene collagen type $\mathrm{X}$ and MMP-13 exhibited a significant decrease. Subsequently, inflammation was controlled and the cartilage was repaired. According to these results, cartilage scaffolds may be used as MSC carriers to further promote the secretion of anti-inflammatory cytokines and enhance anti-inflammatory effects in co-culture.

Existing studies have reported that cartilage anabolic factors, such as TGF- $\beta$, fibroblast grow th factor and IGF-1, that can restore the function of chondrocytes, cartilage-protective drugs and matrix components, such as chondroitin sulfate and hyaluronic acid, can decrease IL-1 $\beta$-mediated NF- $\kappa$ B activation (174-176), thereby inhibiting cartilage breakdown, delaying OA development and repairing damaged cartilage. Park et al (177) described an injectable microsphere made from genipin cross-linked gelatin and discovered that the anti-inflammatory cytokines released from the gelatin microspheres, mediated by inflammatory cells, may alleviate inflammation in chondrocytes activated by IL- $1 \beta$ and lipopolysaccharide. The results have demonstrated that such biomaterial-based methods can be used to synchronize drug release during the inflammatory process, thereby extending anti-inflammatory cytokine therapeutic efficacy and retention times. Moutos et al (178) produced two hemispheric scaffolds with varying configurations constructed from a $3 \mathrm{D}$ polyester ( $\varepsilon$-caprolactone). A scaffold-mediated lentiviral transfecting technique has been used for the genetic modification of ADMSCs in the scaffold to produce high levels of anti-inflammatory cytokines for treating OA in an exogenously regulated and induced manner. Levinson et al (179) observed that heparin can covalently combine with a variety of hyaluronic acids to form hydrogels, therefore achieving continuous release of TGF- $\beta 1$ and enabling MSCs to mature into cartilage tissue without the use of any additional growth factors. The results demonstrated that cartilage 
scaffolds coated with drugs or anti-inflammatory cytokines for the treatment of OA may strongly induce anti-inflammatory cytokine expression or cause sustained release of anti-inflammatory cytokines. Therefore, the application of drugs, growth factors, anti-inflammatory cytokines and proinflammatory cytokines is expected to become the focus of studies on the clinical application of CTE scaffolds in the future. Bionic scaffolds have the potential for cartilage repair and regeneration, but they also have certain limitations. Even when several materials are combined, the cartilage damage may not be fully repaired (179). Therefore, future research should focus on further optimizing scaffold preparation technology and related processes, explore the selection and proportion of different scaffold materials used, or introduce different types of drugs, growth factors and cytokines, in an attempt to overcome the current restrictions associated with cartilage injury repair and regeneration. Furthermore, future CTE should also aim to employ simpler preparations of scaffolding with improved stability and more effective scaffold materials, therefore realizing clinical transformation as soon as possible.

In summary, OA and relevant repair procedures may be improved by regulating proinflammatory and anti-inflammatory cytokines via CTE technology. However, CTE technology is still faced with major obstacles, including the selection of source cells and scaffolds, dedifferentiation and amplification procedures, timing for chondrocyte expansion prior to implantation, loss of chondrocytes and high costs. In the future, different methods may be combined for the effective treatment of OA, including advanced scaffolds, highly differentiated chondrocytes, 3D-printed engineering structures, appropriate lubrication and improvement of the proinflammatory environment. This will occur by regulating the effects of proinflammatory and anti-inflammatory cytokines, which may greatly promote the regeneration of articular cartilage (180). However, the aim of CTE is to ensure that the repaired cartilage will regain its basic function, which is to support weight, by mimicking the properties and structure of natural cartilage. A previous study demonstrated that CTE can successfully repair cartilage or osteochondral defects in pigs and meniscus defects in dogs (178). However, this has only been tested on animal models, and the safety issues associated with the extrapolation of animal experimental results to humans have not yet been resolved. Thus, CTE has not been used in clinical practice to date and it is difficult to evaluate its actual efficacy in humans.

\section{Conclusion}

Proinflammatory cytokines contribute to the release of other inflammatory mediators and trigger cartilage degeneration and destruction. Anti-inflammatory cytokines inhibit the actions of proinflammatory cytokines, promote chondrocyte proteoglycan and Col II synthesis, and delay OA progression (2). The imbalance between OA-related inflammatory cytokines may cause abnormal metabolism in the knee cartilage, ultimately destroying the normal knee joint structure. After further understanding of the regulation of chondrocytes and synovium by proinflammatory and anti-inflammatory cytokines, it can be inferred that early molecular cytological clinical intervention in $\mathrm{OA}$, such as inducing the expression of anabolic cytokines while inhibiting that of catabolic cytokines, so that chondrocytes or subchondral osteocytes and synovial cells can achieve a balance of catabolism based on self-repair, will still represent an obstacle in the future (7-9). As stated in the present review, it has been hypothesized that blocking the IL- $1 \beta$ signaling pathway may provide a new direction for the treatment of OA. Furthermore, TGF- $\beta$ may be a focus of future research, as it contributes to the differentiation of MSCs.

The application of drugs, growth factors, anti-inflammatory cytokines and CTE is expected to become the focus of clinical research in the future. Moreover, scaffolds loaded with growth factors, anti-inflammatory cytokines or drugs can endogenously reduce the levels of inflammatory cytokines, promote anti-inflammatory cytokine expression and create optimal conditions for cartilage reproduction (181). However, previous studies often paid attention to the function of a single cytokine, while they ignored the potential synergistic effect of different cytokines (182-184). In the cartilage microenvironment, even small fluctuations in concentration due to the decomposition of several cytokines may cause degradation and destruction of the cartilage matrix (185). Furthermore, even partial cytokines can either repair damaged cartilage or inhibit chondrocyte function and destroy cartilage (186). Therefore, in CTE, the production of cytokines, activation time, number of receptors and the interactions between various cytokines must be further investigated. Therefore, the role of cytokines should be carefully considered in the study of OA, both as independent factors and in combination. Investigating cytokines may help fully elucidate the contributors and triggers involved, identify the relevant conditions and effects resulting from complex interactions, understand the main contradictions between various factors, enable us to alter molecular mechanisms based on CTE techniques and regulate the intra-articular microenvironment, thereby improving the overall efficacy of OA treatment. This approach may lead to important breakthroughs in OA research.

\section{Acknowledgements}

Not applicable.

\section{Funding}

The present review was supported by the National Natural Science Foundation of China (grant no. 81672234).

\section{Availability of data and materials}

Not applicable.

\section{Authors' contributions}

SL was responsible for producing the tables and searching the literature, as well as being a major contributor in writing the manuscript. ZD was mainly responsible for revising the manuscript. KC was responsible for making the figures. SJ contributed to the conception of the study. FZ made substantial contributions to conception and design. YY and ZF were 
involved in drafting the manuscript or revising it critically for important intellectual content. HX contributed significantly to manuscript preparation, and approved the final version. JX and WZ were responsible for funding support and reviewing the article. All authors read and approved the final manuscript. Data authentication is not applicable.

\section{Ethics approval and consent to participate}

Not applicable.

\section{Patient consent for publication}

Not applicable.

\section{Competing interests}

The authors declare that they have no competing interests.

\section{References}

1. Abramoff B and Caldera FE: Osteoarthritis: Pathology, diagnosis, and treatment options. Med Clin North Am 104: 293-311, 2020.

2. Goldring MB and Goldring SR: Articular cartilage and subchondral bone in the pathogenesis of osteoarthritis. Ann NY Acad Sci 1192: 230-237, 2010.

3. Xia B, Di Chen, Zhang J, Hu S, Jin H and Tong P: Osteoarthritis pathogenesis: A review of molecular mechanisms. Calcif Tissue Int 95: 495-505, 2014

4. Zhang Q, Ji Q, Wang X, Kang L, Fu Y, Yin Y, Li Z, Liu Y, $\mathrm{Xu} \mathrm{X}$ and Wang Y: SOX9 is a regulator of ADAMTSs-induced cartilage degeneration at the early stage of human osteoarthritis. Osteoarthritis Cartilage 23: 2259-2268, 2015.

5. Tortorella MD and Malfait AM: Will the real aggrecanase(s) step up: Evaluating the criteria that define aggrecanase activity in osteoarthritis. Curr Pharm Biotechnol 9: 16-23, 2008.

6. Matsuo M, Nishida K, Yoshida A, Murakami T and Inoue H: Expression of caspase-3 and -9 relevant to cartilage destruction and chondrocyte apoptosis in human osteoarthritic cartilage. Acta Med Okayama 55: 333-340, 2001.

7. Abdel-Sayed P and Pioletti DP: Strategies for improving the repair of focal cartilage defects. Nanomedicine (Lond) 10: 2893-2905, 2015.

8. Medvedeva EV, Grebenik EA, Gornostaeva SN, Telpuhov VI, Lychagin AV, Timashev PS and Chagin AS: Repair of damaged articular cartilage: Current approaches and future directions. Int J Mol Sci 19: 2366, 2018.

9. Hunter DJ and Bierma-Zeinstra S: Osteoarthritis. Lancet 393 1745-1759, 2019.

10. Rhee SM, You HJ and Han SK: Injectable tissue-engineered soft tissue for tissue augmentation. J Korean Med Sci 29 (Suppl 3): S170-S175, 2014

11. Schott EM, Farnsworth CW, Grier A, Lillis JA, Soniwala S, Dadourian GH, Bell RD, Doolittle ML, Villani DA, Awad H, et al: Targeting the gut microbiome to treat the osteoarthritis of obesity. JCI Insight 3: e95997, 2018.

12. Kuo SJ, Yang WH, Liu SC, Tsai $\mathrm{CH}$, Hsu $\mathrm{HC}$ and Tang $\mathrm{CH}$ Transforming growth factor $\beta 1$ enhances heme oxygenase 1 expression in human synovial fibroblasts by inhibiting microRNA 519b synthesis. PLoS One 12: e0176052, 2017.

13. Wang $\mathrm{T}$ and He C: Pro-inflammatory cytokines: The link between obesity and osteoarthritis. Cytokine Growth Factor Rev 44: 38-50, 2018.

14. Kapoor M, Martel-Pelletier J, Lajeunesse D, Pelletier JP and Fahmi H: Role of proinflammatory cytokines in the pathophysiology of osteoarthritis. Nat Rev Rheumatol 7: 33-42,2011.

15. Nguyen L, Sharma A, Chakraborty C, Saibaba B, Ahn ME and Lee SS: Review of prospects of biological fluid biomarkers in osteoarthritis. Int J Mol Sci 18: 601, 2017.

16. Mabey T, Honsawek S, Tanavalee A, Yuktanandana P, Wilairatana V and Poovorawan Y: Plasma and synovial fluid inflammatory cytokine profiles in primary knee osteoarthritis. Biomarkers 21 : 639-644, 2016
17. Boehme KA and Rolauffs B: Onset and progression of human osteoarthritis-can growth factors, inflammatory cytokines, or differential miRNA expression concomitantly induce proliferation, ECM Degradation, and inflammation in articular cartilage? Int J Mol Sci 19: 2282, 2018.

18. Goldring MB and Goldring SR: Osteoarthritis. J Cell Physiol 213: 626-634, 2007.

19. Sirikaew N, Chomdej S, Tangyuenyong S, Tangjitjaroen W, Somgird C, Thitaram C and Ongchai S: Proinflammatory cytokines and lipopolysaccharides up regulate MMP-3 and MMP-13 production in Asian elephant (Elephas maximus) chondrocytes: Attenuation by anti-arthritic agents. BMC Vet Res 15: 419, 2019.

20. Ho YJ, Lu JW, Ho LJ, Lai JH, Huang HS, Lee CC, Lin TY, Lien SB, Lin LC, Chen LW, et al: Anti-inflammatory and anti-osteoarthritis effects of Cm-02 and Ck-02. Biochem Biophys Res Commun 517: 155-163, 2019.

21. Fearing BV and Van Dyke ME: In vitro response of macrophage polarization to a keratin biomaterial. Acta Biomater 10: 3136-3144, 2014

22. Dinarello CA: Overview of the interleukin-1 family of ligands and receptors. Semin Immunol 25: 389-393, 2013.

23. Melchiorri C, Meliconi R, Frizziero L, Silvestri T, Pulsatelli L, Mazzetti I, Borzì RM, Uguccioni M and Facchini A: Enhanced and coordinated in vivo expression of inflammatory cytokines and nitric oxide synthase by chondrocytes from patients with osteoarthritis. Arthritis Rheum 41: 2165-2174, 1998.

24. Massicotte F, Lajeunesse D, Benderdour M, Pelletier JP, Hilal G, Duval N and Martel-Pelletier J: Can altered production of interleukin-1beta, interleukin-6, transforming growth factor-beta and prostaglandin $\mathrm{E}(2)$ by isolated human subchondral osteoblasts identify two subgroups of osteoarthritic patients. Osteoarthritis Cartilage 10: 491-500, 2002.

25. Farahat MN, Yanni G, Poston R and Panayi GS: Cytokine expression in synovial membranes of patients with rheumatoid arthritis and osteoarthritis. Ann Rheum Dis 52: 870-875, 1993.

26. Sohn DH, Sokolove J, Sharpe O, Erhart JC, Chandra PE, Lahey LJ, Lindstrom TM, Hwang I, Boyer KA, Andriacchi TP and Robinson WH: Plasma proteins present in osteoarthritic synovial fluid can stimulate cytokine production via Toll-like receptor 4. Arthritis Res Ther 14: R7, 2012.

27. Wojdasiewicz P, Poniatowski $Ł A$ and Szukiewicz D: The role of inflammatory and anti-inflammatory cytokines in the pathogenesis of osteoarthritis. Mediators Inflamm 2014: 561459, 2014.

28. Burrage PS, Mix KS and Brinckerhoff CE: Matrix metalloproteinases: Role in arthritis. Front Biosci 11: 529-543, 2006.

29. Verma P and Dalal K: ADAMTS-4 and ADAMTS-5: Key enzymes in osteoarthritis. J Cell Biochem 112: 3507-3514, 2011.

30. Koshy PJ, Lundy CJ, Rowan AD, Porter S, Edwards DR, Hogan A, Clark IM and Cawston TE: The modulation of matrix metalloproteinase and ADAM gene expression in human chondrocytes by interleukin-1 and oncostatin M: A time-course study using real-time quantitative reverse transcription-polymerase chain reaction. Arthritis Rheum 46: 961-967, 2002.

31. El Mansouri FE, Chabane N, Zayed N, Kapoor M, Benderdour M, Martel-Pelletier J, Pelletier JP, Duval N and Fahmi H: Contribution of H3K4 methylation by SET-1A to interleukin-1-induced cyclooxygenase 2 and inducible nitric oxide synthase expression in human osteoarthritis chondrocytes. Arthritis Rheum 63: 168-179, 2011.

32. Gilman SC, Chang J, Zeigler PR, Uhl J and Mochan E: Interleukin-1 activates phospholipase A2 in human synovial cells. Arthritis Rheum 31: 126-130, 1988.

33. Hardy MM, Seibert K, Manning PT, Currie MG, Woerner BM, Edwards D, Koki A and Tripp CS: Cyclooxygenase 2-dependent prostaglandin E2 modulates cartilage proteoglycan degradation in human osteoarthritis explants. Arthritis Rheum 46: 1789-1803, 2002.

34. Lotz M: The role of nitric oxide in articular cartilage damage. Rheum Dis Clin North Am 25: 269-282, 1999.

35. Haynes MK, Hume EL and Smith JB: Phenotypic characterization of inflammatory cells from osteoarthritic synovium and synovial fluids. Clin Immunol 105: 315-325, 2002.

36. Afonso V, Champy R, Mitrovic D, Collin P and Lomri A: Reactive oxygen species and superoxide dismutases: Role in joint diseases. Joint Bone Spine 74: 324-329, 2007.

37. Bodmer JL, Schneider P and Tschopp J: The molecular architecture of the TNF superfamily. Trends Biochem Sci 27: 19-26, 2002

38. Hosseinzadeh A, Kamrava SK, Joghataei MT, Darabi R, ShakeriZadeh A, Shahriari M, Reiter RJ, Ghaznavi H and Mehrzadi S: Ap MMR-21332-279469 optosis signaling pathways in osteoarthritis and possible protective role of melatonin. J Pineal Res 61: 411-425, 2016. 
39. MacEwan DJ: TNF receptor subtype signalling: Differences and cellular consequences. Cell Signal 14: 477-492, 2002.

40. Grell M, Douni E, Wajant H, Löhden M, Clauss M, Maxeiner B, Georgopoulos S, Lesslauer W, Kollias G, Pfizenmaier K and Scheurich P: The transmembrane form of tumor necrosis factor is the prime activating ligand of the $80 \mathrm{kDa}$ tumor necrosis factor receptor. Cell 83: 793-802, 1995.

41. Hsu H, Xiong J and Goeddel DV: The TNF receptor 1-associated protein TRADD signals cell death and NF-kappaB activation. Cell 81: 495-504, 1995.

42. Hsu H, Huang J, Shu HB, Baichwal V and Goeddel DV: TNF-dependent recruitment of the protein kinase RIP to the TNF receptor-1 signaling complex. Immunity 4: 387-396, 1996.

43. Varfolomeev E, Goncharov T, Fedorova AV, Dynek JN Zobel K, Deshayes K, Fairbrother WJ and Vucic D: c-IAP1 and c-IAP2 are critical mediators of tumor necrosis factor alpha (TNFalpha)-induced NF-kappaB activation. J Biol Chem 283: 24295-24299, 2008

44. O'Donnell MA, Legarda-Addison D, Skountzos P, Yeh WC and Ting AT: Ubiquitination of RIP1 Regulates an NF-kappaBIndependent cell-death switch in TNF signaling. Curr Biol 17: 418-424, 2007

45. Ea CK, Deng L, Xia ZP, Pineda G and Chen ZJ: Activation of IKK by TNF alpha requires site-specific ubiquitination of RIP1 and polyubiquitin binding by NEMO. Mol Cell 22: 245-257, 2006.

46. Bunning RA and Russell RG: The effect of tumor necrosis factor alpha and gamma-interferon on the resorption of human articular cartilage and on the production of prostaglandin $\mathrm{E}$ and of caseinase activity by human articular chondrocytes. Arthritis Rheum 32: 780-784, 1989.

47. Campbell IK, Piccoli DS, Roberts MJ, Muirden KD and Hamilton JA: Effects of tumor necrosis factor and on resorption of human articular cartilage and production of plasminogen activator by human articular chondrocytes. Arthritis Rheum 33: $542-552,1990$.

48. Lefebvre V, Peeters-Joris C and Vaes G: Modulation by interleukin 1 and tumor necrosis factor of production of collagenase, tissue inhibitor of metalloproteinases and collagen types in differentiated and dedifferentiated articular chondrocytes. Biochim Biophys Acta 1052: 366-378, 1990.

49. Meyer FA, Yaron I and Yaron M: Synergistic, additive, and antagonistic effects of interleukin-1 beta, tumor necrosis factor alpha, and gamma-interferon on prostaglandin E, hyaluronic acid, and collagenase production by cultured synovial fibroblasts. Arthritis Rheum 33: 1518-1525, 1990.

50. Saklatvala J: Tumour necrosis factor alpha stimulates resorption and inhibits synthesis of proteoglycan in cartilage. Nature 322 547-549, 1986.

51. van den Berg WB: Anti-cytokine therapy in chronic destructive arthritis. Arthritis Res 3: 18-26, 2001

52. Brennan FM, Chantry D, Jackson AM, Maini RN and Feldmann M: Cytokine production in culture by cells isolated from the synovial membrane. J Autoimmun 2 (Suppl 1): S177-S186, 1989.

53. O'Byrne E, Blancuzzi V, Wilson DE, Wong M and Jeng AY: Elevated substance $\mathrm{P}$ and accelerated cartilage degradation in rabbit knees injected with interleukin-1 and tumor necrosis factor. Arthritis Rheum 33: 1023-1028, 1990.

54. Pettipher ER, Higgs GA and Henderson B: Interleukin 1 induces leukocyte infiltration and cartilage proteoglycan degradation in the synovial joint. Proc Natl Acad Sci USA 83: 8749-8753, 1986.

55. van Beuningen HM, Arntz OJ and van den Berg WB: In vivo effects of interleukin-1 on articular cartilage. Prolongation of proteoglycan metabolic disturbances in old mice. Arthritis Rheum 34: 606-615, 1991.

56. Ding X, Zhang Y, Huang Y, Liu S, Lu H and Sun T: Cadherin-11 involves in synovitis and increases the migratory and invasive capacity of fibroblast-like synoviocytes of osteoarthritis. Int Immunopharmacol 26: 153-161, 2015.

57. Liu S, Cao C, Zhang Y, Liu G, Ren W, Ye Y and Sun T: PI3K/Akt inhibitor partly decreases TNF- $\alpha$-induced activation of fibroblast-like synoviocytes in osteoarthritis. J Orthop Surg Res 14: 425, 2019.

58. Porée B, Kypriotou M, Chadjichristos C, Beauchef G, Renard E, Legendre F, Melin M, Gueret S, Hartmann DJ, Malléin-Gerin F, et al: Interleukin-6 (IL-6) and/or soluble IL-6 receptor down-regulation of human type II collagen gene expression in Articular chondrocytes requires a decrease of $\mathrm{Sp} 1 \cdot \mathrm{Sp} 3$ ratio and of the binding activity of both factors to the COL2A1 promoter. J Biol Chem 283: 4850-4865, 2008.
59. Rowan AD, Koshy PJ, Shingleton WD, Degnan BA, Heath JK, Vernallis AB, Spaull JR, Life PF, Hudson K and Cawston TE: Synergistic effects of glycoprotein 130 binding cytokines in combination with interleukin-1 on cartilage collagen breakdown. Arthritis Rheum 44: 1620-1632, 2001.

60. Cawston TE, Curry VA, Summers CA, Clark IM, Riley GP, Life PF, Spaull JR, Goldring MB, Koshy PJ, Rowan AD and Shingleton WD: The role of oncostatin $\mathrm{M}$ in animal and human connective tissue collagen turnover and its localization within the rheumatoid joint. Arthritis Rheum 41: 1760-1771, 1998.

61. Scanzello CR, Umoh E, Pessler F, Diaz-Torne C, Miles T, Dicarlo E, Potter HG, Mandl L, Marx R, Rodeo S, et al: Local cytokine profiles in knee osteoarthritis: Elevated synovial fluid interleukin-15 differentiates early from end-stage disease. Osteoarthritis Cartilage 17: 1040-1048, 2009.

62. Honsawek S, Deepaisarnsakul B, Tanavalee A, Yuktanandana P, Bumrungpanichthaworn P, Malila S and Saetan N: Association of the IL-6-174G/C gene polymorphism with knee osteoarthritis in a Thai population. Genet Mol Res 10: 1674-1680, 2011.

63. Attur MG, Patel RN, Abramson SB and Amin AR: Interleukin-17 up-regulation of nitric oxide production in human osteoarthritis cartilage. Arthritis Rheum 40: 1050-1053, 1997.

64. Ryu JH, Yang S, Shin Y, Rhee J, Chun CH and Chun JS: Interleukin- 6 plays an essential role in hypoxia-inducible factor $2 \alpha$-induced experimental osteoarthritic cartilage destruction in mice. Arthritis Rheum 63: 2732-2743, 2011.

65. Kwan Tat S, Padrines M, Théoleyre S, Heymann D and Fortun Y: IL-6, RANKL, TNF-alpha/IL-1: Interrelations in bone resorption pathophysiology. Cytokine Growth Factor Rev 15: 49-60, 2004.

66. Chenoufi HL, Diamant M, Rieneck K, Lund B, Stein GS and Lian JB: Increased mRNA expression and protein secretion of interleukin-6 in primary human osteoblasts differentiated in vitro from rheumatoid and osteoarthritic bone. J Cell Biochem 81: 666-678, 2001

67. Sakao K, Takahashi KA, Arai Y, Saito M, Honjo K, Hiraoka N, Asada H, Shin-Ya M, Imanishi J, Mazda O and Kubo T: Osteoblasts derived from osteophytes produce interleukin-6, interleukin-8, and matrix metalloproteinase-13 in osteoarthritis. J Bone Miner Metab 27: 412-423, 2009.

68. Ding X, Cao Y, Xing Y, Ge S, Lin M and Li J: TIMP-1 mediates inflammatory and immune response to IL-6 in adult orbital xanthogranulomatous disease. Ocul Immunol Inflamm 28: 288-297, 2020.

69. De Hooge ASK, van de Loo FAJ, Bennink MB, Bennink MB, Arntz OJ, de Hooge P and van den Berg WB: Male IL-6 gene Knock Out mice developed more advanced osteoarthritis upon aging. Osteoarthritis Cartilage 13: 66-73, 2005.

70. Steel JC, Waldmann TA and Morris JC: Interleukin-15 biology and its therapeutic implications in cancer. Trends Pharmacol Sci 33: 35-41, 2012.

71. Perera LP: Interleukin 15: Its role in inflammation and immunity. Arch Immunol Ther Exp (Warsz) 48: 457-464, 2000.

72. Waldmann TA and Tagaya Y: The multifaceted regulation of interleukin-15 expression and the role of this cytokine in NK cell differentiation and host response to intracellular pathogens. Annu Rev Immunol 17: 19-49, 1999.

73. Baslund B, Tvede N, Danneskiold-Samsoe B, Larsson P, Panayi G, Petersen J, Petersen LJ, Beurskens FJ, Schuurman J, van de Winkel JG, et al: Targeting interleukin-15 in patients with rheumatoid arthritis: A proof-of-concept study. Arthritis Rheum 52: 2686-2692, 2005

74. Mcinnes IB, al-Mughales J, Field M, Leung BP, Huang FP, Dixon R, Sturrock RD, Wilkinson PC and Liew FY: The role of interleukin-15 in T-cell migration and activation in rheumatoid arthritis. Nat Med 2: 175-182, 1996.

75. Tao Y, Qiu X, Xu C, Sun B and Shi C: Expression and correlation of matrix metalloproteinase-7 and interleukin-15 in human osteoarthritis. Int J Clin Exp Pathol 8: 9112-9118, 2015.

76. Santos Savio A, Machado Diaz AC, Chico Capote A, Miranda Navarro J, Rodríguez Alvarez Y, Bringas Pérez R, Estévez del Toro $M$ and Guillen Nieto GE: Differential expression of pro-inflammatory cytokines IL-15Ralpha, IL-15, IL-6 and TNFalpha in synovial fluid from rheumatoid arthritis patients. BMC Musculoskelet Disord 16: 51, 2015.

77. Badolato R, Ponzi AN, Millesimo M, Notarangelo LD and Musso T: Interleukin-15 (IL-15) induces IL-8 and monocyte chemotactic protein 1 production in human monocytes. Blood 90: 2804-2809, 1997.

78. Sun JM, Sun LZ, Liu J, Su BH and Shi L: Serum interleukin-15 levels are associated with severity of pain in patients with knee osteoarthritis. Dis Markers 35: 203-206, 2013. 
79. Chang SH and Dong C: Signaling of interleukin-17 family cytokines in immunity and inflammation. Cell Signal 23: 1069-1075, 2011

80. Zhang X, Angkasekwinai P, Dong C and Tang H: Structure and function of interleukin-17 family cytokines. Protein Cell 2 : 26-40, 2011.

81. Korn T, Bettelli E, Oukka M and Kuchroo VK: IL-17 and Th17 cells. Annu Rev Immunol 27: 485-517, 2009.

82. Pawłowska J, Mikosik A, Soroczynska-Cybula M, Jóźwik A Łuczkiewicz P, Mazurkiewicz S, Lorczyński A, Witkowski JM and Bryl E: Different distribution of CD4 and CD8 T cells in synovial membrane and peripheral blood of rheumatoid arthritis and osteoarthritis patients. Folia Histochem Cytobiol 47: 627-632, 2009.

83. Ishii $H$, Tanaka $H$, Katoh K, Nakamura H, Nagashima $M$ and Yoshino S: Characterization of infiltrating T cells and Th1/Th2-type cytokines in the synovium of patients with osteoarthritis. Osteoarthritis Cartilage 10: 277-281, 2002.

84. Suurmond J, Dorjée AL, Boon MR, Knol EF, Huizinga TW, Toes RE and Schuerwegh AJ: Mast cells are the main interleukin 17-positive cells in anticitrullinated protein antibody-positive and -negative rheumatoid arthritis and osteoarthritis synovium. Arthritis Res Ther 13: R150, 2011.

85. Liu Y, Peng H, Meng Z and Wei M: Correlation of IL-17 Level in synovia and severity of knee osteoarthritis. Med Sci Monit 21: $1732-1736,2015$

86. Koenders MI, Marijnissen RJ, Devesa I, Lubberts E, Joosten LA, Roth J, van Lent PL, van de Loo FA and van den Berg WB Tumor necrosis factor-interleukin-17 interplay induces S100A8, interleukin-1 $\beta$, and matrix metalloproteinases, and drives irreversible cartilage destruction in murine arthritis: Rationale for combination treatment during arthritis. Arthritis Rheum 63: 2329-2339, 2011.

87. Honorati MC, Cattini L and Facchini A: VEGF production by osteoarthritic chondrocytes cultured in micromass and stimulated by IL-17 and TNF-alpha. Connect Tissue Res 48: 239-245, 2007.

88. Honorati MC, Neri S, Cattini L and Facchini A: Interleukin-17, a regulator of angiogenic factor release by synovial fibroblasts. Osteoarthritis Cartilage 14: 345-352, 2006.

89. Lubberts E, Joosten LA, van de Loo FA, van den Gersselaar LA and van den Berg WB: Reduction of interleukin-17-induced inhibition of chondrocyte proteoglycan synthesis in intact murine articular cartilage by interleukin- 4 . Arthritis Rheum 43 : 1300-1306, 2000.

90. Okamura H, Tsutsui H, Komatsu T, Yutsudo M, Hakura A, Tanimoto T, Torigoe K, Okura T, Nukada Y, Hattori K, et al: Cloning of a new cytokine that induces IFN-gamma production by T cells. Nature 378: 88-91, 1995.

91. Ghayur T, Banerjee S, Hugunin M, Butler D, Herzog L, Carter A, Quintal L, Sekut L, Talanian R, Paskind M, et al: Caspase-1 processes IFN-gamma-inducing factor and regulates LPS-induced IFN-gamma production. Nature 386: 619-623 1997.

92. Malemud CJ: Cytokines as therapeutic targets for osteoarthritis BioDrugs 18: 23-35, 2004.

93. Joosten LA, Radstake TR, Lubberts E, van den Bersselaar LA, van Riel PL, van Lent PL, Barrera P and van den Berg WB: Association of interleukin-18 expression with enhanced levels of both interleukin-1beta and tumor necrosis factor alpha in knee synovial tissue of patients with rheumatoid arthritis. Arthritis Rheum 48: 339-347, 2003.

94. Joosten LAB, Smeets RL, Koenders MI, van den Bersselaar LA, Helsen MM, Oppers-Walgreen B, Lubberts E, Iwakura Y, van de Loo FA and van den Berg WB: Interleukin-18 promotes joint inflammation and induces interleukin-1-driven cartilage destruction. Am J Pathol 165: 959-967, 2004

95. Inoue $\mathrm{H}$, Hiraoka $\mathrm{K}$, Hoshino $\mathrm{T}$, Okamoto $\mathrm{M}$, Iwanaga $\mathrm{T}$, Zenmyo M, Shoda T, Aizawa H and Nagata K: High levels of serum IL-18 promote cartilage loss through suppression of aggrecan synthesis. Bone 42: 1102-1110, 2008.

96. John T, Kohl B, Mobasheri A, Ertel W and Shakibaei M: Interleukin-18 induces apoptosis in human articular chondrocytes. Histol Histopathol 22: 469-482, 2007.

97. Dai SM, Shan ZZ, Nishioka K and Yudoh K: Implication of interleukin 18 in production of matrix metalloproteinases in Articular chondrocytes in arthritis: Direct effect on chondrocytes may not be pivotal. Ann Rheum Dis 64: 735-742, 2005.

98. Powers R, Garrett DS, March CJ, Frieden EA, Gronenborn AM and Clore GM: The high-resolution, three-dimensional solution structure of human interleukin- 4 determined by multidimensional heteronuclear magnetic resonance spectroscopy. Biochemistry 32: 6744-6762, 1993.
99. Wlodawer A, Pavlovsky A and Gustchina A: Crystal structure of human recombinant interleukin-4 at 2.25 A resolution. FEBS Lett 309: 59-64, 1992.

100. Carr C, Aykent S, Kimack NM and Levine AD: Disulfide assignments in recombinant mouse and human interleukin 4 Biochemistry 30: 1515-1523, 1991.

101. Mueller TD, Zhang JL, Sebald W and Duschl A: Structure, binding, and antagonists in the IL-4/IL-13 receptor system. Biochim Biophys Acta 1592: 237-250, 2002.

102. Schlaak JF, Pfers I, Meyer Zum Büschenfelde KH and Märker-Hermann E: Different cytokine profiles in the synovial fluid of patients with osteoarthritis, rheumatoid arthritis and seronegative spondylarthropathies. Clin Exp Rheumatol 14: 155-162, 1996

103. Brown MA and Hural J: Functions of IL-4 and control of its expression. Crit Rev Immunol 17: 1-32, 1997.

104. Wang P, Wu P, Siegel MI, Egan RW and Billah MM: Interleukin (IL)-10 inhibits nuclear factor kappa B (NF kappa B) activation in human monocytes. IL-10 and IL-4 suppress cytokine synthesis by different mechanisms. J Biol Chem 270: 9558-9563, 1995.

105. te Velde AA, Huijbens RJ, Heije K, de Vries JE and Figdor CG: Interleukin-4 (IL-4) inhibits secretion of IL-1beta, tumor necrosis factor alpha, and human IL- 6 by human monocytes. Blood 76: 1392-1397, 1990

106. Paul WE: Interleukin-4: A prototypic immunoregulatory lymphokine. Blood 77: 1859-1870, 1991.

107. Vannier E, Miller MC and Dinarello CA: Coordinated antiinflammatory effects of interleukin 4: Interleukin 4 suppresses interleukin 1 production but up-regulates gene expression and synthesis of interleukin 1 receptor antagonist. Proc Natl Acad Sci USA 89: 4076-4080, 1992

108. Hart PH, Vitti GF, Burgess DR, Whitty GA, Piccoli DS and Hamilton JA: Potential anti-inflammatory effects of interleukin 4: Suppression of human monocyte tumor necrosis factor alpha, interleukin 1, and prostaglandin E2. Proc Natl Acad Sci USA 86: 3803-3807, 1989.

109. Yeh LA, Augustine AJ, Lee P, Riviere LR and Sheldon A Interleukin-4, an inhibitor of cartilage breakdown in bovine articular cartilage explants. J Rheumatol 22: 1740-1746, 1995.

110. Van Meegeren ME, Roosendaal G, Jansen NW, Wenting MJ, van Wesel AC, van Roon JA and Lafeber FP: IL-4 alone and in combination with IL-10 protects against blood-Induced cartilage damage. Osteoarthritis Cartilage 20: 764-772, 2012.

111. van Lent PL, Holthuysen AE, Slöetjes A, Lubberts E and van den Berg WB: Local overexpression of adeno-viral IL-4 protects cartilage from metallo proteinase-induced destruction during immune complex-mediated arthritis by preventing activation of pro-MMPs. Osteoarthritis Cartilage 10: 234-243, 2002

112. Doi H, Nishida K, Yorimitsu M, Komiyama T, Kadota Y, Tetsunaga T, Yoshida A, Kubota S, Takigawa M and Ozaki T: Interleukin-4 downregulates the cyclic tensile stress-induced matrix metalloproteinases-13 and cathepsin B expression by rat normal chondrocytes. Acta Medica Okayama 62: 119-126, 2008.

113. Yorimitsu M, Nishida K, Shimizu A, Doi H, Miyazawa S Komiyama T, Nasu Y, Yoshida A, Watanabe S and Ozaki T: Intra-articular injection of interleukin-4 decreases nitric oxide production by chondrocytes and ameliorates subsequent destruction of cartilage in instability-induced osteoarthritis in rat knee joints. Osteoarthritis Cartilage 16: 764-771, 2008.

114. von Kaeppler EP, Wang Q, Raghu H, Bloom MS, Wong H and Robinson WH: Interleukin 4 promotes anti-inflammatory macrophages that clear cartilage debris and inhibits osteoclast development to protect against osteoarthritis. Clin Immunol 229 : $108784,2021$.

115. Shah SS and Mithoefer K: Current Applications of growth factors for knee cartilage repair and osteoarthritis treatment. Curr Rev Musculoskelet Med 13: 641-650, 2020.

116. McAlindon TE, Teale JD and Dieppe PA: Levels of insulin related growth factor 1 in osteoarthritis of the knee. Ann Rheum Dis 52: 229-231, 1993.

117. McQuillan DJ, Handley CJ, Campbell MA, Bolis S, Milway VE and Herington AC: Stimulation of proteoglycan biosynthesis by serum and insulin-like growth factor-I in cultured bovine articular cartilage. Biochem J 240: 423-430, 1986

118. van Osch GJ, van den Berg WB, Hunziker EB, Hunziker EB and Häuselmann HJ: Differential effects of IGF-1 and TGF beta-2 on the assembly of proteoglycans in pericellular and territorial matrix by cultured bovine articular chondrocytes. Osteoarthritis Cartilage 6: 187-195, 1998 
119. Sah RL, Chen AC, Grodzinsky AJ and Trippel SB: Differential effects of bFGF and IGF-I on matrix metabolism in calf and adult bovine cartilage explants. Arch Biochem Biophys 308: 137-147, 1994

120. Yaeger PC, Masi TL, de Ortiz JL, Binette F, Tubo R and McPherson JM: Synergistic action of transforming growth factor-beta and insulin-like growth factor-I induces expression of type II collagen and aggrecan genes in adult human articular chondrocytes. Exp Cell Res 237: 318-325, 1997.

121. Madry H, Kaul G, Cucchiarini M, Stein U, Zurakowski D, Remberger K, Menger MD, Kohn D and Trippel SB: Enhanced repair of articular cartilage defects in vivo by transplanted chondrocytes overexpressing insulin-like growth factor I (IGF-I) Gene Ther 12: 1171-1179, 2005.

122. Fortier LA, Mohammed HO, Lust G and Nixon AJ: Insulin-like growth factor-I enhances cell-based repair of articular cartilage. J Bone Joint Surg Br 84: 276-288, 2002.

123. Davies LC, Blain EJ, Gilbert SJ, Caterson B and Duance VC: The potential of IGF-1 and TGFbetal for promoting 'adult' articular cartilage repair: An in vitro study. Tissue Eng Part A 14: 1251-1261, 2008.

124. Longobardi L, O'Rear L, Aakula S, Johnstone B, Shimer K, Chytil A, Horton WA, Moses HL and Spagnoli A: Effect of IGF-I in the chondrogenesis of bone marrow mesenchymal stem cells in the presence or absence of TGF-beta signaling. J Bone Miner Res 21: 626-636, 2006.

125. Morisset S, Frisbie DD, Robbins PD, Nixon AJ and McIlwraith CW: IL-1ra/IGF-1 gene therapy modulates repair of microfractured chondral defects. Clin Orthop Relat Res 462: 221-228, 2007.

126. Mushtaq T, Bijman P, Ahmed SF and Farquharson C: Insulin-like growth factor-I augments chondrocyte hypertrophy and reverses glucocorticoid-mediated growth retardation in fetal mice metatarsal cultures. Endocrinology 145: 2478-2486, 2004.

127. Koike M, Yamanaka Y, Inoue M, Tanaka H, Nishimura R and Seino Y: Insulin-like growth factor-1 rescues the mutated FGF receptor 3 (G380R) expressing ATDC5 cells from apoptosis through phosphatidylinositol 3-kinase and MAPK. J Bone Miner Res 18: 2043-2051, 2003

128. Fytili P, Giannatou E, Karachalios T, Malizos K and Tsezou A: Interleukin-10G and interleukin-10R microsatellite polymorphisms and osteoarthritis of the knee. Clin Exp Rheumatol 23: 621-627, 2005

129. Jansen NWD, Roosendaal G, Hooiveld MJJ, Bijlsma JW van Roon JA, Theobald M and Lafeber FP: Interleukin-10 protects against blood-induced joint damage. Br J Haematol 142. 953-961, 2008.

130. Wang Y and Lou S: Direct protective effect of interleukin-10 on articular chondrocytes in vitro. Chin Med J (Engl) 114: 723-725, 2001.

131. Behrendt P, Preusse-Prange A, Klüter T, Haake M, Rolauffs B, Grodzinsky AJ, Lippross S and Kurz B: IL-10 reduces apoptosis and extracellular matrix degradation after injurious compression of mature articular cartilage. Osteoarthritis Cartilage 24 1981-1988, 2016.

132. Rudwaleit M, Yin Z, Siegert S, Grolms M, Radbruch A, Braun J and Sieper J: Response to methotrexate in early rheumatoid arthritis is associated with a decrease of $\mathrm{T}$ cell derived tumour necrosis factor alpha, increase of interleukin 10, and predicted by the initial concentration of interleukin 4. Ann Rheum Dis 59: 311-314, 2000.

133. Zeng L, Kempf H, Murtaugh LC, Sato ME and Lassar AB: Shh establishes an Nkx3.2/Sox9 autoregulatory loop that is maintained by BMP signals to induce somitic chondrogenesis. Genes Dev 16: 1990-2005, 2002.

134. Chimal-Monroy J, Rodriguez-Leon J, Montero JA, Gañan Y, Macias D, Merino R and Hurle JM: Analysis of the molecular cascade responsible for mesodermal limb chondrogenesis: Sox genes and BMP signaling. Dev Biol 257: 292-301, 2003.

135. Horbelt D, Denkis A and Knaus P: A portrait of transforming growth factor $\beta$ superfamily signalling: Background matters. In J Biochem Cell Biol 44: 469-474, 2012.

136. Massagué J, Blain SW and Lo RS: TGFbeta signaling in growth control, cancer, and heritable disorders. Cell 103:295-309, 2000.

137. Siegel PM and Massagué J: Cytostatic and apoptotic actions of TGF-beta in homeostasis and cancer. Nat Rev Cancer 3 : 807-821, 2003.

138. Santo VE, Gomes ME, Mano JF and Reis RL: Controlled release strategies for bone, cartilage, and osteochondral engineering-part I: Recapitulation of native tissue healing and variables for the design of delivery systems. Tissue Eng Part B Rev 19: 308-326, 2013.
139. Cals FL, Hellingman CA, Koevoet W, Baatenburg de Jong RJ and van Osch GJ: Effects of transforming growth factor- $\beta$ subtypes on in vitro cartilage production and mineralization of human bone marrow stromal-derived mesenchymal stem cells J Tissue Eng Regen Med 6: 68-76, 2012.

140. Fortier LA, Barker JU, Strauss EJ, McCarrel TM and Cole BJ: The role of growth factors in cartilage repair. Clin Orthop Relat Res 469: 2706-2715, 2011.

141. Zhang RK, Li GW, Zeng C, Lin CX, Huang LS, Huang GX, Zhao C, Feng SY and Fang H: Mechanical stress contributes to osteoarthritis development through the activation of transforming growth factor beta 1 (TGF- $\beta 1)$. Bone Joint Res 7: 587-594, 2018

142. Rosen DM, Stempien SA, Thompson AY, Brennan JE, Ellingsworth LR and Seyedin SM: Differentiation of rat mesenchymal cells by cartilage-inducing factor. Enhanced phenotypic expression by dihydrocytochalasin B. Exp Cell Res 165: 127-138, 1986.

143. Seyedin SM, Thompson AY, Bentz H, Rosen DM, McPherson JM, Conti A, Siegel NR, Galluppi GR and Piez KA: Cartilage-inducing factor-A. Apparent identity to transforming growth factor-beta. J Biol Chem 261: 5693-5695, 1986.

144. Kato Y, Iwamoto M, Koike T, Suzuki F and Takano Y: Terminal differentiation and calcification in rabbit chondrocyte cultures grown in centrifuge tubes: Regulation by transforming growth factor beta and serum factors. Proc Natl Acad Sci USA 85: 9552-9556, 1988 .

145. Leonard CM, Fuld HM, Frenz DA, Downie SA, Massagué J and Newman SA: Role of transforming growth factor-beta in chondrogenic pattern formation in the embryonic limb: Stimulation of mesenchymal condensation and fibronectin gene expression by exogenenous TGF-beta and evidence for endogenous TGF-beta-like activity. Dev Biol 145: 99-109, 1991.

146. Xu C, Oyajobi BO, Frazer A, Kozaci LD, Russell RG and Hollander AP: Effects of growth factors and interleukin-1 alpha on proteoglycan and type II collagen turnover in bovine nasal and articular chondrocyte pellet cultures. Endocrinology 137: 3557-3565, 1996.

147. Ito T, Sawada R, Fujiwara Y and Seyama Y and Tsuchiya T: FGF-2 suppresses cellular senescence of human mesenchymal stem cells by down-regulation of TGF-beta2. Biochem Biophys Res Commun 359: 108-114, 2007.

148. Lin Y, Luo E, Chen X, Liu L, Qiao J, Yan Z, Li Z, Tang W, Zheng X and Tian W: Molecular and cellular characterization during chondrogenic differentiation of adipose tissue-derived stromal cells in vitro and cartilage formation in vivo. J Cell Mol Med 9: 929-939, 2005.

149. Bian L, Zhai DY, Tous E, Rai R, Mauck RL and Burdick JA Enhanced MSC chondrogenesis following delivery of TGF- $\beta 3$ from alginate microspheres within hyaluronic acid hydrogels in-vitro and in vivo. Biomaterials 2: 6425-6434, 2011.

150. Bhang SH, Jeon JY, La WG, Seong JY, Hwang JW, Ryu SE and Kim BS: Enhanced chondrogenic marker expression of human mesenchymal stem cells by interaction with both TGF- $\beta 3$ and hyaluronic acid. Biotechnol Appl Biochem 58: 271-276, 2011.

151. Barry F, Boynton RE, Liu B and Murphy JM: Chondrogenic differentiation of mesenchymal stem cells from bone marrow: Differentiation-dependent gene expression of matrix components. Exp Cell Res 268: 189-200, 2001.

152. Dave K and Gomes VG: Interactions at scaffold interfaces: Effect of surface chemistry, structural attributes and bioaffinity. Mater Sci Eng C Mater Biol Appl 105: 110078, 2019.

153. Huang BJ, Hu JC and Athanasiou KA: Cell-based tissue engineering strategies used in the clinical repair of articular cartilage. Biomaterials 98: 1-22, 2016.

154. Yang J, Zhang YS, Yue K and Khademhosseini A: Cell-laden hydrogels for osteochondral and cartilage tissue engineering. Acta Biomater 57: 1-25, 2017.

155. Kim YG, Choi J and Kim K: Mesenchymal stem cell-derived exosomes for effective cartilage tissue repair and treatment of osteoarthritis. Biotechnol J 15: e2000082, 2020.

156. Pittenger MF, Mackay AM, Beck SC, Jaiswal RK, Douglas R, Mosca JD, Moorman MA, Simonetti DW, Craig S and Marshak DR: Multilineage potential of adult human mesenchymal stem cells. Science 284: 143-147, 1999.

157. Traggiai E, Volpi S, Schena F, Gattorno M, Ferlito F, Moretta L and Martini A: Bone marrow-derived mesenchymal stem cells induce both polyclonal expansion and differentiation of B cells isolated from healthy donors and systemic lupus erythematosus patients. Stem Cells 6: 562-569, 2008 
158. Rasmusson I, Le Blanc K, Sundberg B and Ringdén O: Mesenchymal stem cells stimulate antibody secretion in human B cells. Scand J Immunol 65: 336-343, 2007.

159. Spaggiari GM, Capobianco A, Becchetti S, Mingari MC and Moretta L: Mesenchymal stem cell-natural killer cell interactions: Evidence that activated NK cells are capable of killing MSCs, whereas MSCs can inhibit IL-2-induced NK-cell proliferation. Blood 107: 1484-1490, 2006.

160. Liang X, Ding Y, Zhang Y, Tse HF and Lian Q: Paracrine mechanisms of mesenchymal stem cell-based therapy: Current status and perspectives. Cell Transplant 23: 1045-1059, 2014.

161. Théry C, Witwer KW, Aikawa E, Alcaraz MJ, Anderson JD, Andriantsitohaina R, Antoniou A, Arab T, Archer F, Atkin-Smith GK, et al: Minimal information for studies of extracellular vesicles 2018 (MISEV2018): A position statement of the international society for extracellular vesicles and update of the MISEV2014 guidelines. J Extracell Vesicles 7: 1535750, 2018.

162. Li X, Ellman M, Muddasani P, Wang JH, Cs-Szabo G, van Wijnen AJ and Im HJ: Prostaglandin E2 and its cognate EP receptors control human adult articular cartilage homeostasis and are linked to the pathophysiology of osteoarthritis. Arthritis Rheum 60: 513-523, 2009.

163. Cosenza S, Ruiz M, Toupet K, Jorgensen C and Noël D Mesenchymal stem cells derived exosomes and microparticles protect cartilage and bone from degradation in osteoarthritis. Sci Rep 7: 16214, 2017.

164. Song Y, Zhang TJ, Li Y and Gao Y: Mesenchymal stem cells decrease $\mathrm{M} 1 / \mathrm{M} 2$ ratio and alleviate inflammation to improve limb ischemia in mice. Med Sci Monit 26: e923287, 2020.

165. Toh WS, Zhang B, Lai RC and Lim SK: Immune regulatory targets of mesenchymal stromal cell exosomes/small extracellular vesicles in tissue regeneration. Cytotherapy 20: 1419-1426, 2018

166. Chang YH, Wu KC, Harn HJ, Lin SZ and Ding DC: Exosomes and stem cells in degenerative disease diagnosis and therapy. Cell Transplant 27: 349-363, 2018.

167. Wang Y, Yu D, Liu Z, Zhou F, Dai J, Wu B, Zhou J, Heng BC, Zou XH, Ouyang $\mathrm{H}$ and Liu $\mathrm{H}$ : Exosomes from embryonic mesenchymal stem cells alleviate osteoarthritis through balancing synthesis and degradation of cartilage extracellular matrix. Stem Cell Res Ther 8: 189, 2017.

168. Temenoff JS and Mikos AG: Review: Tissue engineering for regeneration of articular cartilage. Biomaterials 21: 431-440, 2000

169. Hutmacher DW: Scaffolds in tissue engineering bone and cartilage. Biomaterials 21: 2529-2543, 2000.

170. Zuluaga M, Gregnanin G, Cencetti C, Di Meo C, Gueguen V, Letourneur D, Meddahi-Pellé A, Pavon-Djavid G and Matricardi P: PVA/Dextran hydrogel patches as delivery system of antioxidant astaxanthin: A cardiovascular approach. Biomed Mater 13: 015020, 2017.

171. Jiang T, Heng S, Huang X, Zheng L, Kai D, Loh XJ and Zhao J: Biomimetic poly(poly( $\varepsilon$-caprolactone)-Polytetrahydrofuran urethane) based nanofibers enhanced chondrogenic differentiation and cartilage regeneration. J Biomed Nanotechnol 15: 1005-1017, 2019.

172. Fasolino I, Raucci MG, Soriente A, Demitri C, Madaghiele M, Sannino A and Ambrosio L: Osteoinductive and anti-inflammatory properties of chitosan-based scaffolds for bone regeneration. Mater Sci Eng C Mater Biol Appl 105: 110046, 2019.
173. Bhardwaj N, Singh YP and Mandal BB: Silk fibroin scaffold-based 3D Co-culture model for modulation of chondrogenesis without hypertrophy via reciprocal Cross-talk and paracrine signaling. ACS Biomater Sci Eng 5: 5240-5254, 2019.

174. Campo GM, Avenoso A, Campo S, D'Ascola A, Traina P and Calatroni A: Chondroitin-4-sulphate inhibits NF-kB translocation and caspase activation in collagen-induced arthritis in mice. Osteoarthritis Cartilage 16: 1474-1483, 2008.

175. Avenoso A, D'Ascola A, Scuruchi M, Mandraffino G, Calatroni A, Saitta A, Campo S and Campo GM: Hyaluronan in the experimental injury of the cartilage: Biochemical action and protective effects. Inflamm Res 67: 5-20, 2018.

176. Chen L, Liu J, Guan M, Zhou T, Duan X and Xiang Z: Growth factor and its polymer scaffold-based delivery system for cartilage tissue engineering. Int J Nanomedicine 15: 6097-6111, 2020.

177. Park E, Hart ML, Rolauffs B, Stegemann JP and T Annamalai R: Bioresponsive microspheres for on-demand delivery of anti-inflammatory cytokines for articular cartilage repair. J Biomed Mater Res A 108: 722-733, 2020.

178. Moutos FT, Glass KA, Compton SA, Ross AK, Gersbach CA, Guilak F and Estes BT: Anatomically shaped tissue-engineered cartilage with tunable and inducible anticytokine delivery for biological joint resurfacing. Proc Natl Acad Sci USA 113: E4513-E4522, 2016

179. Levinson C, Lee M, Applegate LA and Zenobi-Wong M: An injectable heparin-conjugated hyaluronan scaffold for local delivery of transforming growth factor $\beta 1$ promotes successful chondrogenesis. Acta Biomater 99: 168-180, 2019.

180. Armiento AR, Stoddart MJ, Alini M and Eglin D: Biomaterials for articular cartilage tissue engineering: Learning from biology. Acta Biomater 65: 1-20, 2018.

181. Qasim M, Chae DS and Lee NY: Advancements and frontiers in nano-based 3D and 4D scaffolds for bone and cartilage tissue engineering. Int J Nanomedicine 14: 4333-4351, 2019.

182. Zhao Y, Li Y, Qu R, Chen X, Wang W, Qiu C, Liu B, Pan X, Liu L, Vasilev K, et al: Cortistatin binds to TNF- $\alpha$ receptors and protects against osteoarthritis. EBioMedicine 41: 556-570, 2019.

183. Cui Z, Crane J, Xie H, Jin X, Zhen G, Li C, Xie L, Wang L, Bian Q, Qiu T, et al: Halofuginone attenuates osteoarthritis by inhibition of TGF- $\beta$ activity and H-type vessel formation in subchondral bone. Ann Rheum Dis 75: 1714-1721, 2016.

184. Chavez RD and Serra R: Scaffoldless tissue-engineered cartilage for studying transforming growth factor beta-mediated cartilage formation. Biotechnol Prog 36: e2897, 2020.

185. Goldring MB, Otero M, Plumb DA, Dragomir C, Favero M, El Hachem K, Hashimoto K, Roach HI, Olivotto E, Borzì RM and Marcu KB: Roles of inflammatory and anabolic cytokines in cartilage metabolism: Signals and multiple effectors converge upon MMP-13 regulation in osteoarthritis. Eur Cell Mater 21: 202-220, 2011

186. Contentin R, Demoor M, Concari M, Desancé M, Audigié F, Branly T and Galéra P: Comparison of the chondrogenic potential of mesenchymal stem cells derived from bone marrow and umbilical cord blood intended for cartilage tissue engineering. Stem Cell Rev Rep 16: 126-143, 2020.

This work is licensed under a Creative Commons Attribution-NonCommercial-NoDerivatives 4.0 International (CC BY-NC-ND 4.0) License. 